\title{
Electrospun nanofibers: A nanotechnological approach for drug delivery and dissolution optimization in poorly water-soluble drugs
}

\author{
Luis Castillo-Henríquez ${ }^{1,2, *}$, Rolando Vargas-Zúñiga ${ }^{1}$, Jorge Pacheco-Molina ${ }^{3}$ and Jose \\ Vega-Baudrit ${ }^{2,4}$ \\ ${ }^{1}$ Physical Chemistry Laboratory, Faculty of Pharmacy, University of Costa Rica, 11501-2060, San José, Costa Rica \\ ${ }^{2}$ National Laboratory of Nanotechnology (LANOTEC), National Center for High Technology (CeNAT), 1174-1200, San \\ José, Costa Rica \\ ${ }^{3}$ Laboratory of Pharmaceutical Technology, Faculty of Pharmacy, University of Costa Rica, 11501-2060, San José, Costa \\ Rica \\ ${ }^{4}$ Laboratory of Polymers (POLIUNA), Chemistry School, National University of Costa Rica, 86-3000, Heredia, Costa Rica \\ *Corresponding Author: E-mail: luis.castillohenriquez@ucr.ac.cr; Tel.: +506-6196-1666; Fax: +506-2511-8315
}

Received: May 01, 2020; Revised: July 02, 2020; Published: July 05, 2020

\begin{abstract}
Electrospinning is a novel and sophisticated technique for the production of nanofibers with high surface area, extreme porous structure, small pore size, and surface morphologies that make them suitable for biomedical and bioengineering applications, which can provide solutions to current drug delivery issues of poorly water-soluble drugs. Electrospun nanofibers can be obtained through different methods asides from the conventional one, such as coaxial, multi-jet, side by side, emulsion, and melt electrospinning. In general, the application of an electric potential to a polymer solution causes a charged liquid jet that moves downfield to an oppositely charged collector, where the nanofibers are deposited. Plenty of polymers that differ in their origin, degradation character and water affinity are used during the process. Physicochemical properties of the drug, polymer(s), and solvent systems need to be addressed to guarantee successful manufacturing. Therefore, this review summarizes the recent progress in electrospun nanofibers for their use as a nanotechnological tool for dissolution optimization and drug delivery systems for poorly water-soluble drugs.
\end{abstract}

(C)2020 by the authors. This article is an open-access article distributed under the terms and conditions of the Creative Commons Attribution license (http://creativecommons.org/licenses/by/4.0/).

\section{Keywords}

Electrospinning; Drug development; Drug loading; Drug release; Nanotechnology; Polymers; Solubility.

\section{Introduction}

Nanofibers can be considered as nanomaterials based on their diameter, because they geometrically fall into the category of one-dimensional nanoscale elements, such as nanotubes and nanorods. However, their highly flexible nature makes them similar to two-dimensional elements and others like globular molecules as well. In addition to that, they can be viewed as nanostructured materials when filled with nanoparticles in order to form a composite. Therefore, nanofibers possess characteristics such as high surface area, extreme porous structure, small pore size and surface morphologies that make them suitable for drug 
development and biomedical applications, providing sophisticated and novel solutions to current drug delivery inconveniences [1-3].

Electrospun nanofibers have been the target of different applications, due to their structure and physicochemical properties. These types of nanofibers have been studied by Schaub et al. based on their regenerative potential in spinal cord injuries $[4,5]$. According to Sundara et al., their 3D architecture makes them very similar to the skin extracellular matrix structure, which allows their use as scaffolds for skin tissue engineering [6]. In addition to that, Miguel et al. have worked with electrospun nanofibers loaded with bioactive molecules for improving wound healing [7]. Another application, sustained release, has been evaluated by Chou et al. for hydrophilic small molecule drugs [8]. Recently, Woon and Sun have developed a charged poly(vinylidene fluoride) (PVDF) nanofiber filter to overcome novel coronavirus (SARS-CoV-2) capture limitations exhibited by N95 and N98 masks. This technology effectively traps virus particles at 100 $\mathrm{nm}$, which reduces the risk of acquiring COVID-19. Their work might set new technologies for protective clothing from biological agents as well [9]. Some other uses that have been given to electrospun nanofibers within the biomedical and pharmaceutical industries are water filtration, cosmetic masks, and nanosensors $[10,11]$.

It is worth mentioning that a wide array of polymer types are being used in the creation of nanofibers, like synthetic, natural, biodegradable, non-degradable or a blend of them. Thanks to the nanotechnological boom, many techniques are available and employed for the manipulation of polymers and nanofibers' preparation [12-14]. Methods can be either chemical or physical; some of these are drawing, melt blowing, template synthesis, sea-island spinning, self-assembly, phase separation and electrospinning [15-20]. Among the mentioned, electrospinning is the most employed method for the production of nanofibers as an alternative delivery strategy for poorly water-soluble drugs that are not suitable for oral administration [21,22]. Also, it is considered as the most efficient technique since it has been recognized as a simple, versatile and low-cost process. Electrospun nanofibers are produced by an electrostatically driven jet of a solid dispersion consisting of a polymer solution. Compared to other conventional solid dispersion techniques, it can produce nanofibers with enhanced dissolution and improved physicochemical properties of active pharmaceutical ingredient' (API) particles, which can be attributed to the amorphization of the enclosed drug [23-26].

However, among the mentioned applications of electrospun nanofibers, the most relevant is their capacity to act as drug delivery systems due to their high loading capacity, faster dissolution kinetics, APIs simultaneous delivery, and encapsulation. These outstanding properties make them attractive for the industry [27-30]. Therefore, the present review focuses on the different electrospinning methods and materials employed for obtaining nanofibers, as well as recent and relevant investigations that have improved the delivery and dissolution performance of poorly water-soluble drugs, including smart nanofibers.

\section{Historical context}

In the $17^{\text {th }}$ century, William Gilbert was the first in documenting research with high voltage direct current applied to a solution. He observed a cone shape when a drop of water was close to electrically charged amber [31]. By the end of the 1800s, many papers had been released regarding the use of 'electrical spinning', using materials such as shellac, beeswax, and others, whilst in the early 1900s, the electrical charge was used mainly to spray liquids, as established by Cooley and Morton in their patents about electrical methods of dispersing fluids $[32,33]$. 
Nevertheless, the first electrospinning patent 'Process and apparatus for preparing artificial threads' came in 1934 by Formhals, where he described an experimental setup characterized by a collecting device, drum wheel and a plate for the production of polymer filaments using electrostatic force, which later was going to be a novel technique in nanotechnology [34]. However, it was not until 1974 when Taniguchi in his publication 'On the basic concept of nanotechnology', that this scientific field was referenced for the first time [35]. Nanotechnology is conceived in its simplest definition as the science and technology that takes place on the nanoscale (1-100 nm). Precisely, due to the previous, it has been possible to obtain novel materials and structures that are integrated into larger systems improving not only chemical, physical and biological properties, but also different kinds of processes [36,37].

Although electrospinning as a polymer-processing technology has been known for more than 80 years, it was not until 1994 when significant studies explored the production of nanofibers through this technique. By that year, the term 'electrospinning' was adopted among the scientific community thanks to the work of different researchers including Doshi, Reneker, and Chun, who demonstrated that many organic polymers can be electrospun into nanofibers $[38,39]$. Since then, significant effort has been done for the study and employment of this nanofiber fabrication technique.

\section{Electrospinning techniques}

It is well known that electrospinning has its origin in 'electrospraying', wherein both cases the application of an electric potential to a polymer solution causes a charged liquid jet that moves downfield to an oppositely charged collector $[40,41]$. Nevertheless, electrospraying is performed using a low viscosity liquid which due to the surface tension produces instability in the jet, resulting in the formation of polymer droplets instead of nanofibers, as occurs in electrospinning when working with polymer solutions of higher viscosity. The process can be done under room temperature unless it is necessary a heat source to keep the polymer molten [41,42].

In addition to that, nanofibers properties will depend on the type of polymer used and the method of manufacture, since there have been some modifications to the conventional electrospinning technique. The methods can be classified as needle or needleless electrospinning, where the latter is represented by roller and wire electrospinning, which offer some advantages over needle methods like the lack of clogging $[43,44]$. However, those advantages are not as significant as the differences within needle systems, thus this review will focus on needle techniques presented in Figure 1. A single needle set-up, like solution electrospinning, is mostly used for research purposes, while multiple systems such as coaxial, multi-jet, side by side, emulsion, and melt electrospinning have been designed to improve nanofibers manufacturing $[45,46]$.

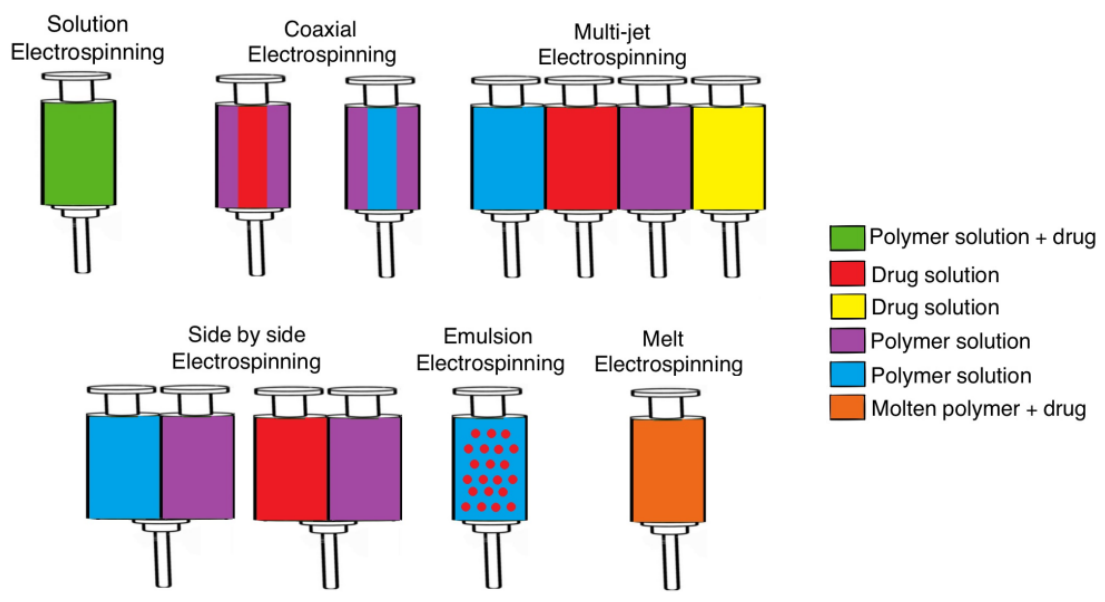

Figure 1. Electrospinning techniques. 


\section{Solution electrospinning}

Also known as co-electrospinning or blending electrospinning, it is conceived as a solid dispersion method that involves the dissolution of a drug in a polymer solution using a suitable solvent. It requires simpler equipment than other fiber manufacturing techniques, but it can create a great variety of products for different applications $[47,48]$. The usual set up design showed in Figure 2 consists of a feeding unit with a spinneret, typically a syringe controlled by a pump that transports the polymer solution. Some novel spinnerets recently used by several research groups for improving the nanofiber fabrication process are rotating disk, plucked string, plated edge, and multiple rings. There is also necessary a high-voltage supplier connected to the spinneret and the collector, charging them oppositely [49-51].

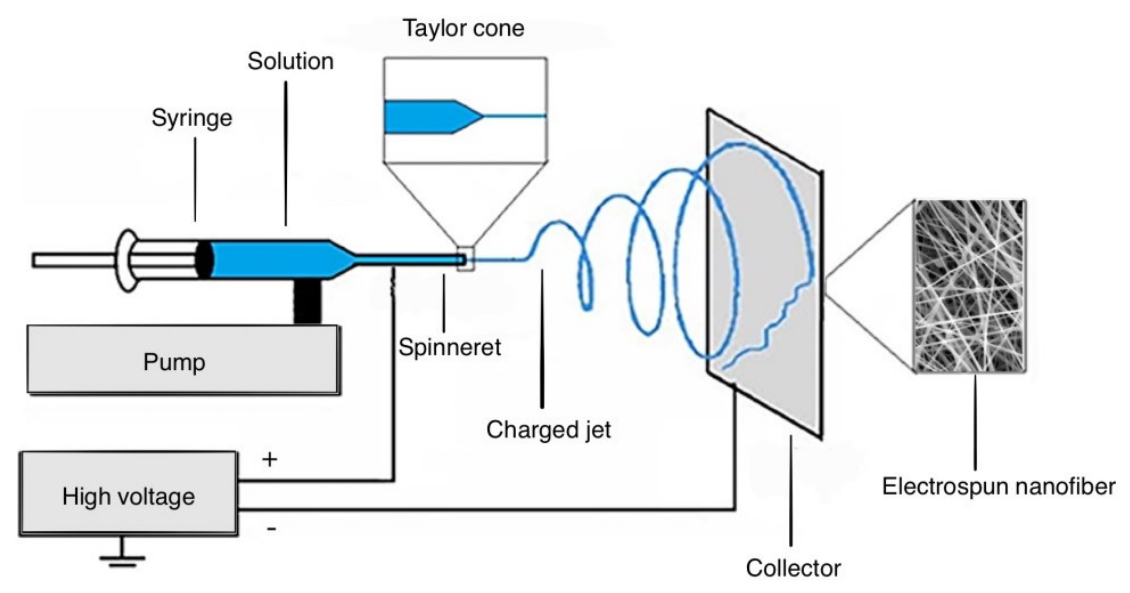

Figure 2. Electrospinning basic set-up design. Adapted with permission from Y. Li et al. Electrospinning in Tissue Engineering. In: A. Haider, S. Haider. Electrospinning: Material, Techniques, and Biomedical Applications p.117-139. Copyright (2016) IntechOpen [51].

Regarding the process, the polymer solution is held by its surface tension at the end of the spinneret or capillary tip. Once the solution is subjected to high voltage by a direct current power supply, the droplet at the tip elongates to develop a conical form known as 'Taylor Cone' [52]. When the electric field or electrostatic repelling force between the spinneret and the collector reaches a critical voltage, it overcomes the surface tension of the polymer solution, resulting in the ejection of a continuously charged jet from the tip of the Taylor cone [53-55].

As it travels to the rotating or stationary collector two main events are worth highlighting. In the first place, the solvent evaporates but not completely, which represents a challenge for research groups due to solvent's toxicity. On the other hand, the fine filament travels following a chaotic trajectory in a whip-like motion, known as bending instability. When it reaches the collector the continuous filament accumulates or deposits to form the nanofiber [56-60].

Tan et al. employed this technique to fabricate vascular grafts made of poly( $\varepsilon$-caprolactone) (PCL), gelatin, and poly(vinyl alcohol) (PVA). The obtained nanofibers rapidly degradated in vivo, also possessed appropriate properties for use in artery replacement, and offered scaffolds with high porosity enhancing cell proliferation and infiltration [61]. In another approach, Ahmed et al. reported the creation of PCL /cellulose nanofibers for the use as biosensor strips [62].

\section{Coaxial electrospinning}

Coaxial electrospinning presents changes regarding the method described in solution electrospinning. In this multiple needle system, two polymer solutions or a polymer and a drug solution with different properties regarding solubility and hydrophilicity, are loaded into individual feeding units to simultaneously 
electrospin from coaxial spinnerets. Since the last ones share an axis, one solution is injected through the inner needle into the concentric outer one at the capillary tip, resulting in a continuous core-shell nanofiber. In addition to that, the principle can be applied to triaxial systems as well, where the electrospun nanofiber will contain a core, a middle layer, and sheath [63-65].

The previously described process allows confining APIs inside the core and controlling drug delivery mainly through diffusion rather than desorption of the surface [66]. Moreover, coaxial electrospinning using hydrophilic and hydrophobic polymers within the composition provides a rich combination of their properties in a single engineered nanofiber while each component maintains its identity. This type of electrospun nanofiber leads to better control of drug diffusion to the medium [67-69].

Wang et al. provided an approach for the design of hypromellose (HPMC)-based hydrophilic composites fabricated through coaxial electrospinning. The core fluid of the electrospun nanofibers was prepared from an electrospinnable solution containing $13 \%(\mathrm{w} / \mathrm{v})$ of HPMC, $2 \%(\mathrm{w} / \mathrm{v})$ of ferulic acid and $3 \%(\mathrm{w} / \mathrm{v})$ of poly(ethylene glycol) (PEG) in a 1:1 ethanol/dichloromethane (DCM) mixture, while ethanol was used as the sheat solvent for the process. The performance of the electrospun nanofibers in the dissolution test revealed to be 10 times faster than casting hydrophilic composites. Therefore, this approach can be useful as a means to obtain carriers for the delivery of poorly water-soluble drugs [70]. Another research published by Wu et al. proposes an alternative approach. In this case, the sheath layer consisted of a solution of poly(vinylpyrrolidone) K60 (PVP) and citric acid, while the core was composed of a PEG 6000 and sodium hydroxide co-dissolving solution [71].

Like in solution electrospinning, the application of a high voltage results in the formation of a Taylor cone. However, in this case, it is compounded and formed by the core solution surrounded by the sheath polymer solution $[72,73]$. This method can solve the problem of those highly unstable substances of biomedical interest like enzymes, which can't be electrospun due to their molecular weight or solubility properties. Furthermore, when these compounds are loaded into the core the sheath structure protects them from the reactive environment [74].

\section{Multi-jet electrospinning}

A multiple spinnerets or nozzles set-up design is readily used for increasing the production rate of electrospun nanofibers due to its simplicity. This method can be classified into three categories: a) single spinneret with multiple jets, b) multiple spinnerets and each one with a single jet, and c) multiple spinnerets with multiple jets per each. Therefore, a mass production increase of nanofibers can be achieved by increasing not only the nozzles but also the tips or holes [75-77].

Multi-jet electrospinning possesses a very similar process compared to the conventional method, where a continuously charged jet trajectory is defined by the electrical field. However, in this system, the jet direction towards the collector is greatly influenced by Coulomb forces caused by neighboring jets. Precisely, one of the major issues of this method is a jet deviation that is exerted by the interaction of electrostatic forces between them, which provokes defects in the nanofibers $[75,78,79]$.

In order to reduce jet repulsion, many approaches have been performed such as increasing the applied voltage, different spinnerets arrangements, and adjusting the distance between them. Regarding that, Liu et al. proposed placing an auxiliary grounded electrode to solve the problem, which improves the production rate as well [80]. Later work from Liu's group evaluated the influence of solution properties including dielectric constant, polarity, conductivity and surface tension on multi-jet electrospinning when using an auxiliary electrode. This time it was found out that solutions with higher dielectric constant (32.2- 
78.6) and larger surface tension $(31.8-41.29 \mathrm{mN} / \mathrm{m})$ are most likely to produce 2-6 jets with short stable length $(1.7-6.9 \mathrm{~mm})$ under the influence of low voltage (5.03-7.13 kV) [81].

\section{Side by side electrospinning}

Sometimes it is necessary to combine blends of polymers using one solvent or different polymer solutions for nanofiber production through electrospinning. However, it is not always possible to manufacture nanofibers this way, since both polymers are required to be thermodynamically miscible when dissolving them in the same solvent. In addition, for polymer solution mixtures, polymer-polymer, polymersolvent and solvent-solvent interactions must be analyzed [82,83].

Thus, side by side electrospinning introduces itself as a means for overcoming these difficulties. This method focuses on controlling viscosity and conductivity of two polymer solutions that do not get into physical contact until they reach the tip of the spinneret, where they are electrospun simultaneously. Therefore, the resulting nanofiber consists of a bicomponent system with good mechanical strength and great thermal stability. In addition to that, it has different properties on both sides, based on the corresponding component placed on each $[84,85]$.

Yu et al. have employed this technique for the fabrication of Janus fibers using a teflon-coated parallel spinneret, which allowed the formation of a Janus Taylor cone for obtaining high quality integrated Janus structures. The electrospun nanofibers had one side composed of PVP K60 and ketoprofen, while the other consisted of ethyl cellulose (EC) and the drug as well. The mentioned biphasic design provided a fast dissolution on PVP K60 side and a sustained release of the remaining drug on the EC side [86]. Later, they produced high quality PVP K60/shellac Janus nanofibers using this electrospinning method, but with the modification of using a structured spinneret comprising two eccentric needles nested into a third one [87].

\section{Emulsion electrospinning}

Proposed by $\mathrm{Xu}$ et al., it has been developing recently as an alternative technique of electrospinning [88]. This novel method allows processing emulsions to encapsulate either hydrophilic or hydrophobic APIs for the manufacturing of core-shell nanofibers, using a single spinneret. The process has been found to enhance encapsulation in the core and to provide better drug stability and bioavailability relevant for the development of advanced drug delivery systems. The release mechanism is mainly controlled by diffusion and enzymatic degradation of the solidified polymers [89-91].

For this purpose, either water-in-oil or oil-in-water emulsions can be electrospun [89]. During the process, the solvent molecules closer to the polymeric jet surface evaporate at a higher rate, which causes a viscosity increase in the outer layer. Then, emulsion droplets are subjected to the electrical field that induces them to condense and stretch into elliptical shapes, but also several other forces have an influence on the charged jet, like Coulomb's and electrostatic forces, which provoke droplet expansion. On the other hand, viscoelastic forces and surface tension control droplet contraction to reduce the interface between the air and the polymeric jet. Finally, when the jet reaches the collector, the solvent has almost completely evaporated [92,93].

Hu et al. investigated the influence of Span 80, sodium dodecyl sulfate (SDS) and poly(ethylene oxide)poly(propylene oxide)-poly(ethylene oxide) triblock copolymer towards the morphological properties of an electrospun poly ( $\varepsilon$-caprolactone) /bovine serum albumin nanofibers. It was found that a $0.4 \%(w / v)$ SDS emulsion produced the most uniform electrospun nanofibers through emulsion electrospinning [94]. In another research, Moydeen et al. employed the technique for the production of core-shell PVA/dextran sulfate nanofibers loaded with ciprofloxacin, which demonstrated to improve the sustained release of the drug compared to the nanofibers obtained by co-electrospinning [95]. 


\section{Melt electrospinning}

This technique is considered one of the most relevant variations of the conventional electrospinning method because instead of using a polymer solution it employs molten polymers for achieving nanofiber production [96,97]. Although molten polymer viscosity will tend to be greater compared to a polymer solution, it is possible to use some other substances as auxiliaries like plasticizers in order to reduce this parameter. When the jet arrives at the collector the solidification process will not be caused by drying or evaporation of a solvent but it will be produced by molten polymer cooling $[98,99]$.

Melt electrospinning stands out for being considered as a green technology in nanofibers manufacturing, which allows exploring new approaches regarding biomedical and bioengineering applications without the restrictions of using solvents, and related issues like incomplete elimination and their toxicity $[100,101]$. In addition to that, it is a promising method for industrial production and commercialization, since it not only increases the production rate of nanofibers but also gets rid of manufacturing costs represented by the use of expensive solvents [102,103].

Larrondo and Manley were the pioneers of this method three decades ago when they tried to produce nanofibers from molten polypropylene (PP) but ended obtaining fibers with diameters greater than $50 \mu \mathrm{m}$ due to high melt viscosity of the polymer [104-106]. Despite that, the technique hadn't been exploited to a great extent until Weimin et al. proposed in 2014 a variant of this method called 'Polymer Melt Differential Electrospinning' (PMDES) [107].

In PMDES scale-up, it was found out that producing multiple jets from one umbrella-shaped spinneret resulted in the obtention of nanofibers with an average diameter of $300 \mathrm{~nm}$, with an efficiency $500-1000$ times higher than solution electrospinning, and about 80 times higher compared to conventional melt electrospinning [107]. However, even the basic method of this technique is still under study, thus process parameters such as melt viscosity and processing temperatures still need special attention and evaluation [108].

\section{Polymers and solvents}

Among the most frequently used materials in nanotechnology, polymers are actively employed in this field for the production of nanofibers by electrospinning. A wide variety of them, from natural and synthetic origins, have been electrospun under different required manufacturing conditions. One can also use polymer blends to obtain nanofibers with different structures such as core-shell, ribbon-like, porous, and aligned. Therefore, polymer properties and functionalities provide nanofibers with desirable characteristics and performance to fulfill the general demands for specialized applications $[109,110]$.

Properties such as hydrophilic and hydrophobic nature of the raw material need to be addressed since they have a major effect on drug release from polymeric nanofiber matrix. Hydrophobic polymers provide limited diffusion of aqueous solutions into the matrix due to their restricted contact angle allowing for longterm release, while hydrophilic polymers cause the diffusion of the API to the medium by their swelling mechanism and their dissolution [111]. Furthermore, polymer crystallinity plays an important role, since amorphous regions provide better access to water molecules compared to crystalline regions. Thus, highly crystalline polymers exhibit a slower release of drugs [112].

The most popular synthetic polymers that have been electrospun are hydroxypropylmethyl cellulose (HPMC), PEO, PVP, sodium carboxymethyl cellulose (NaCMC), PVA, alginates, dextran, PCL, poly(lactic acid) (PLA), poly(glycolic acid) (PGA), poly(lactic acid-co-glycolic acid) (PLGA), and poly(lactide-co-e-caprolactone) (PLCL). Regarding the natural raw materials, the use of chitosan, gelatin, collagen, chitin, fibrinogen, and silk 
fibroin have been reported $[113,114]$. The aforementioned polymers are extensively used in biomedical and bioengineering due to their advantages in manufacturing such as stable mechanical properties, good biocompatibility for some applications such as scaffolds, and biodegradable behavior for drug release [115].

Despite the exceptional properties of polymers and the outstanding advances in nanotechnological manufacturing, not all of them are feasible for use in electrospinning. Moreover, it is required a solvent with the capacity of dissolving both, drug and the polymer. Solubility parameters can be useful for the selection of the most adequate solvent. Therefore, non-soluble polymers like polypropylene (PP), polyethylene (PE), and poly(phenylene sulfide) (PPS) can't be electrospun satisfactorily $[116,117]$.

Polymer solubility is complex due to its molecular weight, size difference compared to the solvent, viscosity of the system and changes in terms of structure. The dissolution process is considered to occur in two stages. First, solvent molecules diffuse slowly through the polymer to produce a swollen gel, where polymer-solvent interactions are expected to break intermolecular polymeric bonds. Then, when all polymer-polymer bonds are broken, a true solution is formed $[118,119]$. In addition to that, polymer solubility in a system can be explained by Gibbs free energy $(\Delta G)[120]$ :

$$
\Delta G=\Delta H-T \Delta S,
$$

where $\Delta H$ is the enthalpy of the process, $T$ stands for temperature and $\Delta S$ is the entropy. An adequate solvent is able to make polymer molecules to expand, while a poor one causes them to collapse [120]. Also, the process temperature influences the suitability of a solvent. Temperatures above Flory-Huggins temperature (i.e. the lowest temperature at which a polymer of infinite molecular weight is completely soluble in a determined solvent) induce polymer's molecules to expand, which reduces Gibbs free energy of the system until it reaches a negative value where the polymer is soluble [121-123].

However, in order to evaluate a solvent for a determined drug-polymer system, researchers frequently employ the triangular diagram or solubility map as the main tool for the estimation, as shown in Figure 3. Also, solvents can be classified according to their ability to dissolve the API and the polymer based on dielectric constant values within the range of interest $[124,125]$. Although a polymer is soluble in a determined solvent, it does not always imply its aptitude to be electrospun for obtaining nanofibers [126].

Since different solvents display different levels of electrospinnability, choosing one entails important features to be taken into consideration besides basic parameters like dielectric constant and relative permittivity. In the first place, there must be a balance in the evaporation rate, so that it is enough to allow the fiber to maintain its integrity when arriving at the collector, but not too fast for causing hardening before it reaches the nanometer range. Furthermore, solvent viscosity and surface tension must not prevent the jet formation or allow the polymer solution to drawn freely from the spinneret $[127,128]$.

A polymer solution constituted by multiple solvents may present manufacturing problems, since solvents with different solubility properties can affect several factors from the polymer and the nanofibers. Polymer chain conformation, viscoelasticity, and critical minimum concentration can be influenced by the selection of the solvent [127]. On the other hand, nanofiber diameter, tensile strength, morphology and crystallinity of the loaded drug can be dramatically modified by the solvent properties [129].

Kathsee et al. worked with a biodegradable polymer blend composed of PLA and butylene adipate-coterephthalate (PBAT) for the manufacturing of electrospun nanofibers. In this opportunity, they explored the effects of solution parameters such as types of binary solvents, solvent mixing ratio, and polymer blend concentration. They performed solubility tests of the PLA/PBAT blend for the selection of a suitable binary solvent system that guarantees electrospinnability, resulting in the use of a 3:2 dichloromethane (DCM)/ 
dimethylformamide (DMF) mixture [130]. Although the benefits of electrospinning encourage more research in this field, the non-toxic profile required for polymers and solvents has been difficult to achieve. This has represented a barrier for fast development and industrialization of the technique since more than $90 \%$ of the electrospun polymer solutions reported in the literature at present contain toxic solvents [131]. However, current trends in research have focused on developing a new generation of electrospun nanofibers with fewer toxicity problems for safe and efficacious therapeutic applications [132].

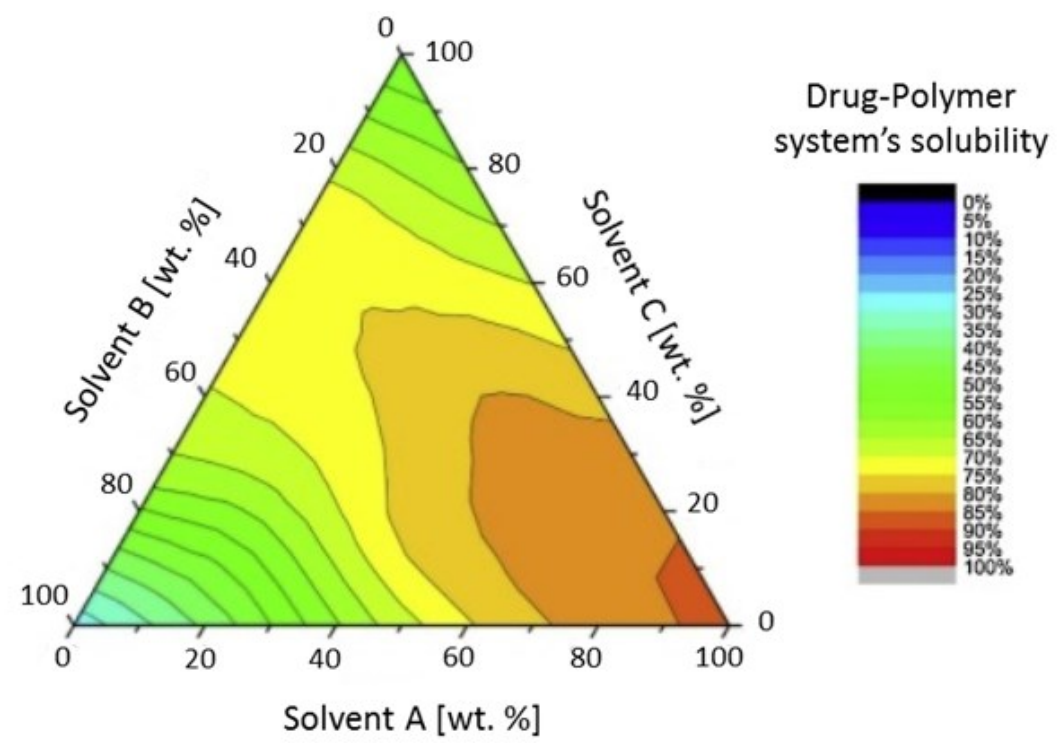

Figure 3. Triangular solubility diagram for a drug-polymer system in solvent mixtures. Adapted with permission from M. Knopp, et al. Comparative Study of Different Methods for the Prediction of Drug-Polymer Solubility. Molecular Pharmaceutics 12(9): 3408-3419. Copyright (2015) American Chemical Society [124].

\section{Drug development through electrospun nanofibers}

\section{Technological issues for the formulation of poorly water-soluble drugs}

Currently, most of the drug products available do not address the growing demand for personalized therapies. Many of them face several formulation challenges due to the physicochemical properties of the APIs, which may prevent the development of a suitable pharmaceutical form that exerts an adequate therapeutic effect [133-135]. However, the rapid growth of nanotechnology intends to contribute greatly to medical and pharmaceutical sciences, providing innovative treatments that can improve patients' lives. Thus, an increasing number of scientists, research groups, industries, and governments are investing millions of dollars for nanotechnological development [136].

It is well known that drug molecules have to be released from the matrix of the pharmaceutical dosage form and then, dissolve in order to be absorbed and to cause the intended therapeutic effect. Nevertheless, both processes are greatly dependent on the physicochemical properties of the API, and the ones from the excipients as well [137]. Consequently, Göke et al. state that poor water solubility is one of the major pharmaceutical challenges for drug development [138]. Amidon et al. classified drug molecules as a function of their aqueous solubility and intestinal permeability in the Biopharmaceutics Classification System (BCS) [139]. Classes II and IV in the BCS have poor solubility due to their complete dose not being possible to dissolve when ingested with a glass of water $(250 \mathrm{ml}$ ) [140-142]. A great majority of new drug molecules and lead compounds are within Class II and IV, and thus present limited oral absorption, slow in vivo dissolution, and low bioavailability [141,143-145].

Therefore, due to the recently increasing number of poorly water-soluble drugs, many methods have 
been employed for improving dissolution [146]. Electrospinning produces amorphous solid dispersions of this kind of drugs in a water-soluble matrix mainly composed of polymers than can enhance their dissolution, where that improvement is explained by the higher solubility exhibited by non-crystalline forms. In addition to that, carriers are mostly hydrophilic, and depending on the preparation method, some can cause a greater increase in the surface area than others $[147,148]$.

Nevertheless, drug-polymer systems are not exempt from presenting incompatibilities, not only chemical but also physical, such as a low degree of miscibility that may lead to an unstable amorphous phase [149]. On the other hand, the presence of polymorphism within the API can make harder the conversion to an amorphous structure, representing a disadvantage for the process [150]. According to Poller et al., a major challenge for electrospinning is the scale-up process and this issue is currently being addressed by both academic and industrial researchers [151-153].

\section{Drug loading}

Synthetic, natural and biologically active substances can be loaded into electrospun nanofibers and it has been widely reported by many research papers. Electrospinning provides nanofibers with a large surface area to volume ratio, which combined with the possibility of choosing an adequate solvent for solubilizing the drug of interest, makes it a technique with high loading capacity. In addition to that, the method is considered as an economic, suitable, stable and improved medium for drug loading that provides control over drug release kinetics [154-156].

Drug loading into electrospun nanofibers can be performed in different ways based on the techniques previously explained. In the first place, the drug can be dissolved directly with the polymer by the same solvent or it may require to be previously dissolved in a small amount of another one in order to be added to the polymer solution, wherein both cases the drug will end embedded in the fabricated nanofiber through co-electrospinning $[154,155]$. A comparative study of curcumin-loaded PCL nanofibers by melt and solution electrospinning was carried out by Lian and Meng. They reported that the active substance did not alter the morphology of melt electrospun nanofibers, which conserved a high crystallinity and could be loaded with a large amount of curcumin in the amorphous state. However, it did cause aggregates in solution electrospinning due to its limited solubility in the solvent system composed of 3:1 DCM/ethanol, which caused jet instability during the process [157]. In another approach made by Zhu et al., coaxial electrospinning was employed to load flurbiprofen for obtaining electrospun PVP/PLGA core-shell nanofibers [158]. Also, for drugs that are not soluble in the same solvent as the polymer, emulsion electrospinning can directly encapsulate lipophilic or hydrophilic drugs within the polymeric matrix. Electrospinning also offers the possibility to load more than one API into the nanofiber thanks to the multijet variant, which is advantageous when it is needed to load lipophilic and hydrophilic drugs in the same three-dimensional structure. Moreover, according to the surface adsorption method, active substances can be incorporated after the electrospinning process by immersing nanofibers in a drug solution as well [159161].

\section{Dissolution optimization}

Nanotechnology has made the use of nanoparticles and nanostructures a trend for increasing the solubility of APIs, which is known to be a limiting step for bioavailability. Because of that, the dissolution test has extended its application not only to solid pharmaceutical dosage forms but to novel drug delivery systems such as electrospun nanofibers. It is well known that solubility is greatly dominated by the nature of the substance functional groups and their interactions with those of the solvent [162]. Electrospinning has allowed the production of nanofibers with poorly water-soluble drugs embedded in hydrophilic 
polymers, which enhances their dissolution rate $[163,164]$.

However, it is clearly stated in the literature that the enhanced solubility and dissolution of drugs exhibited by electrospun nanofibers is mainly due to the presence of the compound in the amorphous state. This can be explained by the fact that many APIs have higher kinetic energy in that arrangement than in the crystalline form [165]. Aside from that, a more homogenous distribution of the drug, increased wettability, lower precipitation, highly porous and specific surface area from the nanostructure also contributes to the optimization of the dissolution rate compared to the commercial pharmaceutical product or the conventional solid dispersions. These improved properties are leading to the design and development of novel formulations including buccal, transdermal and topical dosage forms [166-168].

Nazari et al. worked with solution electrospinning to fabricate different indomethacin buccal films made of Ethocel, HPMC and Tween 80. According to the differential scanning calorimetry (DSC) and X-ray diffraction analysis (XRD), the drug was present in the amorphous state. Dissolution performance was evaluated in vitro in a medium of a buffer at $\mathrm{pH} 6.8$, in which it was found that the presence of Tween 80 accompanied with $5 \%(\mathrm{w} / \mathrm{w})$ of HPMC caused a fast release in the first five minutes, which increased the dissolution rate of the drug in about $62 \%$ compared to the nanofiber produced with the water-insoluble polymer Ethocel [169]. Also, Szabó et al. produced terbinafine hydrochloride buccal films using PVA and chitosan for the electrospinning process, where the nanofibers showed fast and complete dissolution of the drug [170]. In another approach, Adeli prepared several formulations of PVP K90 electrospun nanofibers loaded with irbesartan. All the evaluated prototypes showed an improved dissolution rate, but the one that exhibited the best performance had a 3:7 drug/polymer ratio. In sink conditions, almost $97 \%$ of the drug was released in 60 minutes. Aside to that, saturation solubility increased up to $245.32 \pm 1.77 \mu \mathrm{g} / \mathrm{ml}$, about six times that of the pure drug $(40.55 \pm 1.01 \mu \mathrm{g} / \mathrm{ml})$ due to the electrospun nanofibers-based solid dispersion preparation [171].

\section{Drug delivery and drug release}

Drug delivery systems are designed for improving significantly the therapeutic efficacy and safety of a drug through controlling the targeted-site of action and the release rate. The development of this type of system involves the understanding of drug release kinetics in order to select the most appropriate compounds for the intended purpose. Therefore, controlled release is useful for modifying delivery kinetics, reducing toxicity and side effects, as well as for adjusting therapies according to patients' convenience [172-174].

Electrospun nanofibers have been considered as suitable structures that can control spatially and temporally drug delivery of more than one drug. The first aspect can be achieved by placing the nanofiber at the targeted site by invasive or non-invasive methods to avoid systematic exposure [175-177]. Ravikumar et al. developed a tetrahydro curcumin transdermal patch through electrospinning solution, where the poorly water-soluble active was loaded at a concentration of $8.7 \%$ (w/w of dry polymers) into a 2:1 mix of solutions of PCL $10 \%(w / v)$ and PEG $5 \%(w / v)$ in a chloroform and acetone solvent system, obtaining nanofibers with an average diameter of $400 \pm 20 \mathrm{~nm}$. The cumulative \% release was $95.11 \%$ at 24 hours, exhibiting first-order kinetics that matches Higuchi's diffusion model for which this development might be feasible for once in a day transdermal drug delivery [178].

The obtained nanofibers offer different outstanding properties for hydrophobic active substances, which are explained by their nanostructured nature that improves not only physicochemical and pharmacokinetic properties but also provides protection from enzymatic or chemical degradation. This nanostructure overcomes high drug uptake limitations, exhibits efficient drug transport and has the capacity of encapsulating chemical or biological therapeutic agents during the manufacturing process $[179,180]$. 
Paaver et al. successfully created supersaturated electrospun nanofibers for controlled release of piroxicam made of HPMC and 1,1,1,3,3,3-hexa-fluoro-2-propanol (HFIP) as the solvent. The dry diameter of the nanofibers was in the range of 400-600 nm based on scanning electron microscopy studies (SEM). Solidstate studies of the nanofibers carried by DSC and XRD confirmed the presence of the drug in the amorphous state, but after three months they showed a slow tendency to recrystallize into form III. Physicochemical properties of the nanofibers were strongly dependent on the concentration of HPMC, exhibited short lag-time, no initial burst release and zero-order dissolution kinetics [181].

Electrospun nanofibers are able to achieve controlled release at the targeted site by making use of several polymers, which can be biodegradable or non-degradable. According to that, drug release from non-degradable polymers is performed by diffusion, while release from degradable polymers occurs mainly by matrix erosion. However, the selection of the polymeric matrix is conditioned by the requirements of the application $[182,183]$. When using natural or biodegradable polymers it is necessary to crosslink the matrices for improving the mechanical, thermochemical and structural integrity of electrospun nanofibers, which also enhances sustained and controlled released [184].

Drug release from hydrophilic polymers is possible through surface desorption, diffusion and matrix erosion due to the degradation of the nanofiber caused by enzymes. When nanofibers are constituted by this type of polymers, direct contact with an aqueous solution alters its glassy state and forms a rubbery gel, causing swelling of the polymeric matrix, which transports a drug through its network until it reaches the medium $[185,186]$. For high-swelling polymers, drug release depends on the diffusion through the pores of the nanofibers, while low-swelling polymer release rate is conditioned by the swelling process itself $[187,188]$.

Gordon et al. developed research for the delivery of celecoxib lipophilic nanoparticles, which were formed by loading the poorly water-soluble drug dissolved in a volatile oil-solvent system into the electrospinning aqueous polymer solution composed of a high molecular weight PVA. The obtained hydrophilic electrospun nanofibers enabled fast dissolution and release of celecoxib nanoparticles, since the drug was present in the amorphous state and the average size of the nanoparticles was in the range of 21-93 nm [189].

Polymer, solvent and drug compatibility need to be addressed for achieving reproducible drug release and thus, drug delivery. When the electrospun nanofiber system carries multiple drugs, their affinity to the polymer as well as the interaction between them have to be considered. If any physicochemical interaction is present it may lead to problems regarding the diffusion of the drug, which will result in different release profiles [190-192]. Zhao et al. designed an implantable tissue-engineered scaffold through electrospinning made of a self-coated interfacial layer developed between an inorganic and an organic matrix for timeprogrammed multi-drug release. The scaffold's design propitiated the absence of interactions; the insidelocated drug was ibuprofen, which experienced short-term release for 30 days, while doxorubicin was loaded outside the interfacial layer and showed a sustained long-term release during 90 days [193].

Also, as stated by Haider et al., the chosen electrospinning method and the process itself allow controlling the release kinetics through some critical parameters such as matrix properties, nanofiber diameter, porosity and of course their morphology. However, if the different drugs are loaded by the same electrospinning method, the release will depend on each diffusion coefficient [194]. Thus, different techniques are associated with different rates of release. When drugs are loaded through physical or surface adsorption into the nanofibers this will exhibit short diffusion times, while methods like coaxial electrospinning provide controlled and sustained profiles [195]. 
However, recent research is focusing on developing electrospun nanofibers that are responsive to certain stimuli or feedback factors that start the controlled release of the drug at the targeted site. These novel drug delivery systems are called smart electrospun nanofibers $[196,197]$.

\section{Smart electrospun nanofibers}

Although these systems have experienced considerable progress in the past years, all of them face the same challenges regarding the manufacturing process, quality control and cytotoxicity, which imply a great barrier to faster development [196]. However, it seems that electrospinning can offer a solution to many of the common problems through the selection of a suitable carrier based on the therapeutic goal, material safety profile, drug physicochemical properties, and the route of administration. As presented on Table 1, several types of electrospun smart nanofibers have been developed that respond to certain stimuli such as $\mathrm{pH}$, temperature, magnetic field and electric influence. In addition to that, some of them are responsive to multiple stimuli that cause a physical or chemical change in its arrangement $[198,199]$.

Table 1. Electrospun smart nanofibers applications.

\begin{tabular}{|c|c|c|c|c|}
\hline Smart System & Polymers & Drug & Application & Reference \\
\hline \multirow{3}{*}{ pH-responsive } & Eudragit S100, lecithin & Diclofenac sodium & $\begin{array}{l}\text { Oral-colon targeted drug } \\
\text { delivery. }\end{array}$ & [200] \\
\hline & Eudragit L100 & $\begin{array}{c}\text { Alkaline } \\
\text { phosphatase }\end{array}$ & $\begin{array}{l}\text { Peroral delivery of } \\
\text { proteins. }\end{array}$ & [201] \\
\hline & Eudragit S, Eudragit RS & Indomethacin & Colonic drug delivery. & [202] \\
\hline \multirow[b]{2}{*}{$\begin{array}{l}\text { Thermo- } \\
\text { responsive }\end{array}$} & $\begin{array}{c}\operatorname{Poly}(\mathrm{N}- \\
\text { vinylcaprolactam-co- } \\
\text { methacrylic acid) }\end{array}$ & Ketoprofen & Extended drug release. & [203] \\
\hline & $\begin{array}{c}\text { Poly(di(ethylene glycol) } \\
\text { methyl ether } \\
\text { methacrylate), Ethyl } \\
\text { cellulose }\end{array}$ & Ketoprofen & Extended drug release. & [204] \\
\hline \multirow[t]{2}{*}{$\begin{array}{l}\text { Magnetic field- } \\
\text { responsive }\end{array}$} & $\begin{array}{l}\text { Poly (D,L-lactide-co- } \\
\text { glycolide) }\end{array}$ & Bortezomib & $\begin{array}{l}\text { Implantable device for } \\
\text { endoscopic hyperthermia } \\
\text { treatment and tumor- } \\
\text { triggered controlled drug } \\
\text { release. }\end{array}$ & [205] \\
\hline & Poly( $\varepsilon$-caprolactone) & Ketoconazole & $\begin{array}{c}\text { Slow sustained release for } \\
\text { fungal infections. }\end{array}$ & [206] \\
\hline \multirow{2}{*}{$\begin{array}{l}\text { Electrical field- } \\
\text { responsive }\end{array}$} & $\begin{array}{c}\text { Graphene, Poly( } \varepsilon- \\
\text { caprolactone), Gelatin }\end{array}$ & $\begin{array}{l}\text { Tetracycline } \\
\text { hydrochloride }\end{array}$ & $\begin{array}{c}\text { Neural tissue engineering } \\
\text { and drug delivery. } \\
\text { Delivery through }\end{array}$ & [207] \\
\hline & Poly( $\varepsilon$-caprolactone) & Curcumin & $\begin{array}{c}\text { programmable electrical } \\
\text { devices. }\end{array}$ & [208] \\
\hline \multirow{2}{*}{$\begin{array}{l}\text { Multi stimuli- } \\
\text { responsive }\end{array}$} & $\begin{array}{l}\text { Poly(N- } \\
\text { vinylcaprolactam), Ethyl } \\
\text { cellulose, Eudragit L100 }\end{array}$ & Ketoprofen & $\begin{array}{l}\text { Dual temperature and } \mathrm{pH}- \\
\text { responsive delivery in } \\
\text { lower intestinal tract. }\end{array}$ & [209] \\
\hline & $\begin{array}{c}\text { Poly-N- } \\
\text { isopropylacrylamide, } \\
\text { chitosan }\end{array}$ & Curcumin & $\begin{array}{l}\text { Dual temperature and } \mathrm{pH}- \\
\text { responsive for cancer } \\
\text { targeting. }\end{array}$ & [210] \\
\hline
\end{tabular}

pH-responsive: Potential targeted sites such as tissues and organs differ in their physiological pH value, which implies a lot of interest for research in this stimulus for triggering and modulating drug release. Ideally, pH-responsive electrospun nanofibers should be designed and developed in a way that makes them able to release the drug at a certain $\mathrm{pH}$ close to that caused by a condition or a disease in the biological surroundings [211,212].

Nanofiber drug release is expected to be reduced or completely stopped whenever the condition is 
improved and the microenvironment $\mathrm{pH}$ shifts back to the physiological value. Most polymers used for this purpose are biocompatible and biodegradable containing carboxylic acids or amine groups, which undergo protonation and deprotonation as well as changes in size, shape, and hydrophobicity causing the drug release mostly through a swelling mechanism [213]. Although $\mathrm{pH}$-responsive electrospun nanofibers have been found useful for many drugs, they are not suitable for protein delivery as $\mathrm{pH}$ variations can cause denaturation of these molecules [214].

Thermo-responsive: These systems are composed of polymers that suffer solubility modifications based on the lower critical solution temperature (LCST) (i.e. the temperature at which there is a balance in the competition established by hydrophilic and hydrophobic areas of the polymer chain structure) that is usually close to normothermia $\left(37^{\circ} \mathrm{C}\right)$. Thus, below LCST the polymer is completely miscible, but above that parameter, it is only partially due to a reversible phase transition from a hydrophilic form to a dehydrated or hydrophobic state. The aforementioned transition is an entropy-driven process caused by the release of water molecules upon heating [215]. The polymers used for the development of thermo-responsive smart electrospun nanofibers swell below their LCST, which reduces drug release at normothermia because they retain the loaded hydrophobic drug. On the other hand, a small increase in temperature (e.g. a locally heated tumor) enhances the release because of nanofibers shrinking, caused by the polymer conversion into a hydrophobic form [216-218].

Magnetic field-responsive: Magnetic field stimulus provides advantages compared to the other options since it is well known that it does not affect tissues and its penetration in the body is greater than heat or light, causing neither cell death nor DNA damage $[219,220]$. The magnetic properties allow pharmaceutical nanoparticles to be delivered to a specific site due to the influence of a magnetic field [221]. For the development of these delivery systems, it is necessary to incorporate superparamagnetic iron oxide nanoparticles (SPIONs) with high biocompatibility and low cytotoxicity like $\mathrm{Fe}_{3} \mathrm{O}_{4}$ (magnetite) or $\mathrm{Fe}_{2} \mathrm{O}_{3}$ (maghemite) into the polymers or polymer solution used during the electrospinning process [222,223]. Magnetite and maghemite display superparamagnetism when the diameter of the nanoparticles is smaller than $20 \mathrm{~nm}$, which results in a non-continuing magnetic interaction upon the removal of an external magnetic field [221].

A common developing strategy involves coating the surface of SPIONs with polymers or encapsulating them in a biodegradable matrix to form a nanocomposite known as magnetic responsive polymer composites (MRPCs) [224]. The formation of MRPCs improves not only SPIONs solubility and biocompatibility but also their surface properties for in vivo administration, conferring all of the superparamagnetic related properties to the entire nanocomposite [224]. Magnetically active polymers react to an external magnetic field and exhibit rheological changes or experience mechanical stress. Polymer's magneto-elastic properties can be used to control deformations such as stretching, contraction, and also the movement of MRPCs $[225,226]$.

Electric field-responsive: Electrospun nanofibers constituted by electric-responsive polymers experience changes in their volume and swelling mechanism when exposed to an electric field. Electrospinning of iondoped conducting polymers and polymer composites or coatings has been applied for manufacturing nanofibers intended for electric field-responsive drug delivery system [227-229].

Multi stimuli-responsive: This kind of system represents a new opportunity for electrospun nanofibers with enhanced performance under the influence of two or more signals. Thus, in the case of multiple drugloaded nanofibers, the release of each drug can respond to a different stimulus, according to the respective polymeric matrix and the manufacturing electrospinning technique. In addition to that, drug release can be triggered at the same time or sequentially, due to the influence of combining multiple stimuli $[230,231]$. 


\section{Concluding remarks}

Nanotechnological development through electrospinning is giving the world the opportunity of overcoming the obstacles presented during the design, formulation, and manufacturing of pharmaceutical, biomedical and bioengineering applications. Currently, electrospun nanofibers are at the forefront of nanotechnology, providing the ability to control and manipulate the properties of the obtained nanostructures, which exhibit improved in vitro dissolution performance compared to the conventional solid dispersion systems. Their most important property is related to their large surface area to volume ratio, which is responsible for the optimized performance in combination with particle size reduction and amorphization of the API. Therefore, electrospinning as a formulation strategy that makes use of electrostatic and mechanical forces to spin fibers, is being positioned as a novel and useful method for local and systemic drug delivery of poorly water-soluble drugs. Although the potential benefits from this technique are known, there is still work to do for overcoming safety and scale-up challenges.

Acknowledgements: This study represents a collaborative work between LANOTEC and the Faculty of Pharmacy of the University of Costa Rica. The corresponding author would like to thank LANOTEC for the assessment and the opportunity for an internship.

Conflict of interest: No potential conflict of interest was reported by the authors.

\section{References}

[1] J. Chen, T. Zhang, W. Hua, P. Li, X. Wang. 3D Porous poly (lactic acid)/regenerated cellulose composite scaffolds based on electrospun nanofibers for biomineralization. Colloids and Surfaces $A$ : Physicochemical and Engineering Aspects 585 (2020). https://doi.org/10.1016/i.colsurfa.2019.124048.

[2] R. Ambrus, A. Alshweiat, I. Csóka, G. Ovari, A. Esmail, N. Radacsi. 3D-printed electrospinning setup for the preparation of loratadine nanofibers with enhanced physicochemical properties. International Journal of Pharmaceutics 567 (2019) 1-8. https://doi.org/10.1016/j.ijpharm.2019.118455.

[3] H. Li, Y. Tan, L. Yang, L. Gao, T. Wang, X. Yang, D. Quan. Dissolution evaluation in vitro and bioavailability in vivo of self-microemulsifying drug delivery systems for $\mathrm{pH}$-sensitive drug loratadine. Journal of Microencapsulation 32(2) (2015) 175-80. https://doi.org/10.3109/02652048.2014.985340.

[4] N. Schaub, C. Johnson, B. Cooper, R. Gilbert. Electrospun Fibers for Spinal Cord Injury Research and Regeneration. Journal of Neurotrauma 33(15) (2016) 1405-1415. https://doi.org/10.1089/neu.$\underline{2015.4165 .}$.

[5] N. Schaub. Electrospun fibers: a guiding scaffold for research and regeneration of the spinal cord. Neural Regeneration Research 11(11) (2016) 1764-1765. https://doi.org/10.4103/16735374.194719.

[6] D. Sundaramurthi, U. Krishnan, S. Sethuraman. Electrospun Nanofibers as Scaffolds for Skin Tissue Engineering. Polymer Reviews. 54(2) (2014) 348-376. https://doi.org/10.1080/15583724.2014.$\underline{81374 .}$.

[7] S. Miguel, M. Ribeiro, P. Coutinho, I. Correia. Electrospun Polycaprolactone/Aloe Vera_Chitosan Nanofibrous Asymmetric Membranes Aimed for Wound Healing Applications. Polymers 9(5) (2017) 183. https://doi.org/10.3390/polym9050183. 
[8] S. Chou, D. Carson, K. Woodrow. Current strategies for sustaining drug release from electrospun nanofibers. Journal of Controlled Release 220 (2015) 584-591. https://doi.org/10.1016/i.jconrel.2015.09.008.

[9] W. Woon, Q. Sun. Electrostatic Charged Nanofiber Filter for Filtering Airborne Novel Coronavirus (COVID-19) and Nano-aerosols. Separation and Purification Technology (2020) 116886. https://doi.org/10.1016/j.seppur.2020.116886.

[10] Y. Ding, W. Li, F. Zhang, Z. Liu, N. Ezazi, D. Liu. Electrospun Fibrous Architectures for Drug Delivery, Tissue Engineering and Cancer Therapy. Advanced Functional Materials 29(2) (2019) 1802852. https://doi.org/10.1002/adfm.201802852.

[11] S. Miguel, D. Simões, A. Moreira, R. Sequeira, I. Correia. Production and characterization of electrospun silk fibroin based asymmetric membranes for wound dressing applications. International Journal of Biological Macromolecules 121 (2019) 524-535. https://doi.org/10.1016/j.ijbiomac.2018.10.041.

[12] M.A. Hassan, B.Y. Yeom, A. Wilkie, B. Pourdeyhimi, S.A. Fabrication of nanofiber meltblown membranes and their filtration properties. Journal of Membrane Science 427 (2013) 336-44. https://doi.org/10.1016/j.memsci.2012.09.050.

[13] M. Rolandi, R. Rolandi. Self-assembled chitin nanofibers and applications. Advances in Colloid and Interface Science 207 (2014) 216-222. https://doi.org/10.1016/j.cis.2014.01.019.

[14] H.S. Liao, J. Lin, Y. Liu, P. Huang, A. Jin, X. Chen. Self-assembly mechanisms of nanofibers from peptide amphiphiles in solution and on substrate surfaces. Nanoscale 8(31) (2016) 14814-14820. https://doi.org/10.1039/C6NR04672J.

[15] K. Katsogiannis, G. Vladisavljević, S. Georgiadou. Porous electrospun polycaprolactone (PCL) fibres by phase separation. European Polymer Journal 69 (2015) 284-295. https://doi.org/10.1016/j.eurpolymj.2015.01.028.

[16] Z. Zhang, W. Tu, T. Peijis, C. Bastiaansen. Fabrication and properties of poly(tetrafluoroethylene) nanofibres via sea-island spinning. Polymer 109 (2017) 321-331. https://doi.org/10.1016/j.polymer.2016.12.060.

[17] M. Hammami, M. Krifa, O. Harzallah. Centrifugal force spinning of PA6 nanofibers - processability and morphology of solution-spun fibers. The Journal of The Textile Institute 105(6) (2014) 637-647. https://doi.org/10.1080/00405000.2013.842680.

[18] L. Yu, Z. Shao, L. Xu, M. Wang. High Throughput Preparation of Aligned Nanofibers Using an Improved Bubble-Electrospinning. Polymers 9(12) (2017) 1-9. https://doi.org/10.3390/polym9120658.

[19] G. Rüzgar, M. Birer, S. Tort, F. Acartürk. Studies on Improvement of Water-Solubility of Curcumin With Electrospun Nanofibers. FABAD Journal of Pharmaceutical Sciences 38(3) (2016) 143-149.

[20] O. Kaljević, J. Đuriš, B. Čalija, Z. Lavrić, J. Kristl, S. Ibrić. Application of miscibility analysis and determination of Soluplus solubility map for development of carvedilol-loaded nanofibers. International Journal of Pharmaceutics 533(2) (2017) 445-454. https://doi.org/10.1016/j.ijpharm.2017.05.017.

[21] T. Potrč, S. Baumgartner, R. Roškar, O. Planinšek, Z. Lavrič, J. Kristl. Electrospun polycaprolactone nanofibers as a potential oromucosal delivery system for poorly water-soluble drugs. European Journal of Pharmaceutical Sciences 75 (2015) 101-113. https://doi.org/10.1016/i.eips.2015.04.004.

[22] X. Wang, D. Yu, X. Li, S. Bligh, G. Williams. Electrospun medicated shellac nanofibers for colontargeted drug delivery. International Journal of Pharmaceutics 490(1-2) (2015) 384-390. https://doi.org/10.1016/j.ijpharm.2015.05.077.

[23] N. Schaub, J. Corey. A method to rapidly analyze the simultaneous release of multiple pharmaceuticals from electrospun fibers. International Journal of Pharmaceutics 574 (2020). https://doi.org/10.1016/i.ijpharm.2019.118871.

[24] N. Radacsi, K. Giapis, G. Ovari, P. Szabó, R. Ambrus. Electrospun nanofiber-based niflumic acid capsules with superior physicochemical properties. Journal of Pharmaceutical and Biomedical Analysis 166 (2019) 371-378. https://doi.org/10.1016/i.jpba.2019.01.037. 
[25] A. Balogh, B. Farkas, G. Verreck, J. Mensch, E. Borbás, B. Nagy B. AC and DC electrospinning of hydroxypropylmethylcellulose with polyethylene oxides as secondary polymer for improved drug dissolution. International Journal of Pharmaceutics 505(1-2) (2016) 159-166. https://doi.org/10.1016/j.ijpharm.2016.03.024.

[26] I. Sebe, P. Szabó, B. Kállai, R. Zelkó. Incorporating small molecules or biologics into nanofibers for optimized drug release: A review. International Journal of Pharmaceutics. 494(1) (2015) 516-530. https://doi.org/10.1016/j.ijpharm.2015.08.054.

[27] X. Hu, S. Liu, G. Zhou, Y. Huang, Z. Xie, X. Jing. Electrospinning of polymeric nanofibers for drug delivery applications. Journal of Controlled Release 185 (2014) 12-21. https://doi.org/10.1016/j.jconrel.2014.04.018.

[28] C. Mingjun, Z. Youchen, L. Haoyi, L. Xiangnan, D. Yumei, M. Bubakir. An example of industrialization of melt electrospinning: Polymer melt differential electrospinning. Advanced Industrial and Engineering Polymer Research 2(3) (2019) 110-115. https://doi.org/10.1016/j.aiepr.2019.06.002.

[29] S. Miguel, R. Sequeira, A. Moreira, C. Cabral, A. Mendonça, P. Ferreira. An overview of electrospun membranes loaded with bioactive molecules for improving the wound healing process. European Journal of Pharmaceutics and Biopharmaceutics 139 (2019) 1-22. https://doi.org/10.1016/j.ejpb.2019.03.010.

[30] A. Jahangiri, K. Adibkia. Applications of electrospinning/electrospraying in drug delivery. Bioimpacts 6(1) (2016) 1-2. https://doi.org/10.15171/bi.2016.08.

[31] V. Pillay, C. Dott, Y. Choonara, C. Tyagi, L. Tomar, P. Kumar. A Review of the Effect of Processing Variables on the Fabrication of Electrospun Nanofibers for Drug Delivery Applications. Journal of Nanomaterials (2013) 1-22. https://doi.org/10.1155/2013/789289.

[32] J.F. Cooley. Electrical method of dispersing fluids. US745276A (1903).

[33] W.J. Morton. Method of dispersing fluids. US705691A (1902).

[34] A. Formhals. Process and apparatus for preparing artificial threads. US1975504A (1934).

[35] N. Taniguchi N. On the basic concept of nanotechnology(PART II). Proceedings of the International Conference on Production Engineering (1974) 18-23.

[36] F. Yalcinkaya. A review on advanced nanofiber technology for membrane distillation. Journal of Engineered Fibers and Fabrics 14 (2019) 1-12. https://doi.org/10.1177/1558925018824901.

[37] M. Nasrollahzadeh, S. Mohammad, M. Sajjadi, Z. Issaabadi. An Introduction to Nanotechnology. Interface Science and Technology 28 (2019) 1-27. https://doi.org/10.1016/B978-0-12-8135860.00001-8.

[38] J. Doshi, D. Reneker. Electrospinning process and applications of electrospun fibers. Journal of Electrostatics 35(2-3) (1995) 151-160. https://doi.org/10.1016/0304-3886(95)00041-8.

[39] D. Reneker, I. Chun. Nanometre diameter fibres of polymer, produced by electrospinning. Nanotechnology 7(3) (1996) 216-223.

[40] N. Bock, T. Dargaville, M. Woodruff. Electrospraying of polymers with therapeutic molecules: State of the art. Progress in Polymer Science 37(11) (2012) 1510-1551. https://doi.org/10.1016/j.progpolymsci.2012.03.002.

[41] D. Nguyen, C. Clasen, G. Van den Mooter. Pharmaceutical Applications of Electrospraying. Journal of Pharmaceutical Sciences 105(9) (2016) 2601-2620. https://doi.org/10.1016/j.xphs.2016.04.024.

[42] C. Angammana, S. Jayaram. Fundamentals of electrospinning and processing technologies. Particulate Science and Technology 34(1) (2016) 72-82. https://doi.org/10.1080/02726351.2015.1043678.

[43] F. Yalcinkaya. Preparation of various nanofiber layers using wire electrospinning system. Arabian Journal of Chemistry 12(8) (2019) 5162-5172. https://doi.org/10.1016/j.arabjc.2016.12.012.

[44] X. Wang, T. Lin, X. Wang. Scaling up the production rate of nanofibers by needleless electrospinning from multiple ring. Fibers Polymer 15(5) (2014) 961-965. https://doi.org/10.1007/s12221-014-0961$\underline{x}$. 
[45] S. Miguel, D. Figueira, D. Simões, M. Ribeiro, P. Coutinho, P. Ferreira. Electrospun polymeric nanofibres as wound dressings: A review. Colloids and Surfaces B: Biointerfaces 169 (2018) 60-71. https://doi.org/10.1016/i.colsurfb.2018.05.011.

[46] A. Balaji, M. Vellayappan, A. John, A. Subramanian, S. Jaganathan, E. Supriyanto. An insight on electrospun-nanofibers-inspired modern drug delivery system in the treatment of deadly cancers. RSC Advances 5(71) (2015) 57984-58004. https://doi.org/10.1039/C5RA07595E.

[47] S. Preethi, M. Haritha, C. Viji, N. Selvamurugan. Bone tissue engineering: Scaffold preparation using chitosan and other biomaterials with different design and fabrication techniques. International Journal of Biological Macromolecules 119 (2018) 1228-1239. https://doi.org/10.1016/j.ijbiomac.2018.08.056.

[48] S. Tajbakhsh, F. Hajiali. A comprehensive study on the fabrication and properties of biocomposites of poly(lactic acid)/ceramics for bone tissue engineering. Materials Science and Engineering: $\mathbf{C} 70$ (2017) 897-912. https://doi.org/10.1016/j.msec.2016.09.008.

[49] X. Chen, Y. Zhang, X. He, H. Li, B. Wei, W. Yang. Electrospinning on a plucked string. Journal of Materials Science 54(1) (2019) 901-910. https://doi.org/10.1007/s10853-018-2870-7.

[50] J. Lagaron, A. Solouk, S. Castro, Y. Echegoyen. 3 - Biomedical applications of electrospinning, innovations, and products. In: T. Uyar, E. Kny. Electrospun Materials for Tissue Engineering and Biomedical Applications. Woodhead Publishing, Cambridge, UK, 2017 p. 57-72. https://doi.org/10.1016/B978-0-08-101022-8.00010-7.

[51] Y. Li, T. Bou. Electrospinning in Tissue Engineering. In: A. Haider, S. Haider. Electrospinning: Material, Techniques, and Biomedical Applications. IntechOpen, London, UK, 2016 p.117-139. https://doi.org/10.5772/65836.

[52] G. Taylor, M. Van Dyke. Electrically driven jets. Proceedings of the Royal Society of London A Mathematical and Physical Sciences 313(1515) (1969) 453-475. https://doi.org/10.1098/rspa.1969.0205.

[53] M. Morad, A. Rajabi, M. Razavi, S. Sereshkeh. A Very Stable High Throughput Taylor Cone-jet in Electrohydrodynamics. Scientific Reports 6(1) (2016) 1-10. https://doi.org/10.1038/srep38509.

[54] K. Zhao, W. Wang, Y. Yang, K. Wang, D. Yu. From Taylor cone to solid nanofiber in tri-axial electrospinning: Size relationships. Results in Physics 15 (2019) 102770. https://doi.org/10.1016/i.rinp.2019.102770.

[55] J. He. On the height of Taylor cone in electrospinning. Results in Physics 17 (2020) 103096. https://doi.org/10.1016/i.rinp.2020.103096.

[56] Y. Chiu, Z. Zhang, K. Dziemidowicz, C. Nikoletopoulos, U. Angkawinitwong, J. Chen. The Effect of Solvent Vapor Annealing on Drug-Loaded Electrospun Polymer Fibers. Pharmaceutics 12(2) (2020) 139. https://doi.org/10.3390/pharmaceutics12020139.

[57] J. Xue, J. Xie J, W. Liu, Y. Xia. Electrospun Nanofibers: New Concepts, Materials, and Applications. Accounts of Chemical Research 50(8) (2017) 1976-1987. https://doi.org/10.1021/acs.accounts.7b00218.

[58] N. Ismail, F. Maksoud, N. Ghaddar, K. Ghali, A. Tehrani. Simplified modeling of the electrospinning process from the stable jet region to the unstable region for predicting the final nanofiber diameter. Journal of Applied Polymer Science 133(43) (2016) 44112. https://doi.org/10.1002/app.44112.

[59] M. Šimko, D. Lukáš. Mathematical modeling of a whipping instability of an electrically charged liquid jet. Applied Mathematical Modelling 40(21) (2016) 9565-9583. https://doi.org/10.1016/i.apm.2016.$\underline{06.018 .}$

[60] M. Masuelli, D. Renard. Advances in Physicochemical Properties of Biopolymers (Part 2). Bentham Science Publishers, 2017, p. 497.

[61] Z. Tan, H. Wang, X. Gao, T. Liu, Y. Tan. Composite vascular grafts with high cell infiltration by coelectrospinning. Materials Science and Engineering: C 67 (2016) 369-377. https://doi.org/10.1016/i.msec.2016.05.067. 
[62] F. Ahmed, S. Saleemi, Z. Khatri, M. Abro, I. Kim. Co-electrospun poly( $\varepsilon$-caprolactone)/cellulose nanofibers-fabrication and characterization. Carbohydrate Polymers 115 (2015) 388-393. https://doi.org/10.1016/i.carbpol.2014.09.002.

[63] X. Qin. 3 - Coaxial electrospinning of nanofibers. In: M. Afshari. Electrospun Nanofibers. Woodhead Publishing, Cambridge, UK, 2017, p. 41-71. https://doi.org/10.1016/B978-0-08-100907-9.00003-9.

[64] W. Yu, Q. Ma, X. Li, X. Dong, J. Wang, G. Liu. One-pot coaxial electrospinning fabrication and properties of magnetic-luminescent bifunctional flexible hollow nanofibers. Materials Letters $\mathbf{1 2 0}$ (2014) 126-129. https://doi.org/10.1016/i.matlet.2014.01.076.

[65] H. Zhang, X. Qin, J. Wu, Y. He, H. Du, B. Li. Electrospun core-shell silicon/carbon fibers with an internal honeycomb-like conductive carbon framework as an anode for lithium ion batteries. Journal of Materials Chemistry A 3(13) (2015) 7112-7120. https://doi.org/10.1039/C4TA06044J.

[66] H. Jiang, L. Wang, K. Zhu. Coaxial electrospinning for encapsulation and controlled release of fragile water-soluble bioactive agents. Journal of Controlled Release 193 (2014) 296-303. https://doi.org/10.1016/j.jconrel.2014.04.025.

[67] S. Bandyopadhyay, S. Ghosh, M. Sain. 19 - The use of biobased nanofibres in composites. In: O. Faruk, M. Sain. Biofiber Reinforcements in Composite Materials. Woodhead Publishing, Cambridge, UK, 2015, p. 571-647. https://doi.org/10.1533/9781782421276.5.571.

[68] B. Lee, H. Yang, W. Yu. Fabrication of double-tubular carbon nanofibers using quadruple coaxial electrospinning. Nanotechnology 25(46) (2014) 465602. https://doi.org/10.1088/09574484/25/46/465602.

[69] C. Gualandi, A. Celli, A. Zucchelli, M. Focarete. Nanohybrid Materials by Electrospinning. In: S. Kalia, Y. Haldorai. Organic-Inorganic Hybrid Nanomaterials. Springer International Publishing, Switzerland, 2015, p. 87-142. https://doi.org/10.1007/12 2014281.

[70] Q. Wang, D. Yu, L. Zhang, X. Liu, Y. Deng, M. Zhao. Electrospun hypromellose-based hydrophilic composites for rapid dissolution of poorly water-soluble drug. Carbohydrate Polymers 174 (2017) 617-625. https://doi.org/10.1016/i.carbpol.2017.06.075.

[71] Y. Wu, D. Yu, H. Li, X. Wu, X. Li. Medicated structural PVP/PEG composites fabricated using coaxial electrospinning. e-Polymers 17(1) (2017) 39-44. https://doi.org/10.1515/epoly-2016-0244.

[72] A. Gañán, J. López, M. Herrada, A. Ramos, J. Montanero. Review on the physics of electrospray: From electrokinetics to the operating conditions of single and coaxial Taylor cone-jets, and AC electrospray. Journal of Aerosol Science 125 (2018) 32-56. https://doi.org/10.1016/j.jaerosci.2018.05.002.

[73] X. Wang, Q. Wang, F, Huang, Q. Wei. The morphology of Taylor cone influenced by different coaxial composite nozzle structures. Fibers and Polymers 17 (2016) 624-629. https://doi.org/10.1007/s12221-016-5730-6.

[74] A. Khalf, S. Madihally. Recent advances in multiaxial electrospinning for drug delivery. European Journal of Pharmaceutics and Biopharmaceutics 112 (2017) 1-17. https://doi.org/10.1016/j.ejpb.2016.11.010.

[75] H. SalehHudin, E. Mohamad, W. Mahadi, A. Afifi. Multiple-jet electrospinning methods for nanofiber processing: A review. Materials and Manufacturing Processes 33(5) (2018) 479-498. https://doi.org/10.1080/10426914.2017.1388523.

[76] M. Izzat, Q. Zafar, Z. Ahmad, K. Sulaiman. Humidity sensor based on electrospun MEH-PPV:PVP microstructured composite. RSC Advances 6(42) (2016) 35387-35393. https://doi.org/10.1039/C6RA03628G.

[77] S. Theron, A. Yarin, E. Zussman, E. Kroll. Multiple jets in electrospinning: experiment and modeling. Polymer 46(9) (2005) 2889-2899. https://doi.org/10.1016/j.polymer.2005.01.054.

[78] Y. Zheng, R. Gong, Y. Zeng. Multijet motion and deviation in electrospinning. RSC Advances 5(60) (2015) 48533-48540. https://doi.org/10.1039/C5RA06049D.

[79] Y. Zhang, Z. Cheng, Z. Han, S. Zhao, X. Zhao, L. Kang. Stable multi-jet electrospinning with high throughput using the bead structure nozzle. RSC Advances 8(11) (2018) 6069-6074. https://doi.org/10.1039/C7RA13125A. 
[80] Y. Liu, L. Zhang, X. Sun, J. Liu, J. Fan, D. Huang. Multi-jet electrospinning via auxiliary electrode. Materials Letters 141 (2015) 153-156. https://doi.org/10.1016/i.matlet.2014.11.079.

[81] Y. Wu, L. Wang, J. Fan, W. Shou, B. Zhou, Y. Liu. Multi-Jet Electrospinning with Auxiliary Electrode: The Influence of Solution Properties. Polymers 10(6) (2018) 572. https://doi.org/10.3390/polym10060572.

[82] P. Gupta, G. Wilkes. Some investigations on the fiber formation by utilizing a side-by-side bicomponent electrospinning approach. Polymer 44(20) (2003) 6353-6359. https://doi.org/10.1016/S0032-3861(03)00616-5.

[83] K. Nasouri, A. Shoushtari, M. Mohaddes. Thermodynamic Studies on Polyvinylpyrrolidone Solution Systems Used for Fabrication of Electrospun Nanostructures: Effects of the Solvent. Advances in Polymer Technology 34(3) (2015) 21495. https://doi.org/10.1002/adv.21495.

[84] M. Cai, H. He, X. Zhang, X. Yan, J. Li, F. Chen. Efficient Synthesis of PVDF/PI Side-by-Side Bicomponent Nanofiber Membrane with Enhanced Mechanical Strength and Good Thermal Stability. Nanomaterials 9(1) (2019) 39. https://doi.org/10.3390/nano9010039.

[85] L. Peng, S. Jiang, M. Seuß, A. Fery, G. Lang, T. Scheibel. Two-in-One Composite Fibers With Side-bySide Arrangement of Silk Fibroin and Poly(L-lactide) by Electrospinning. Macromolecular Materials and Engineering 301(1) (2016) 48-55. https://doi.org/10.1002/mame.201500217.

[86] D. Yu, C. Yang, M. Jin, G. Williams, H. Zou, X. Wang. Medicated Janus fibers fabricated using a Tefloncoated side-by-side spinneret. Colloids and Surfaces B: Biointerfaces 138 (2016) 110-116. https://doi.org/10.1016/i.colsurfb.2015.11.055.

[87] D. Yu, J. Li, M. Zhang, R. Williams. High-quality Janus nanofibers prepared using three-fluid electrospinning. Chemical Communications 53(33) (2017) 4542-4545. https://doi.org/10.1039/C7CC01661A.

[88] X. Xu, L. Yang, X. Xu. Ultrafine medicated fibers electrospun from W/O emulsions. Journal of Controlled Release 108(1) (2005) 33-42. https://doi.org/10.1016/i.jconrel.2005.07.021.

[89] C. Zhang, F. Feng, H. Zhang. Emulsion electrospinning: Fundamentals, food applications and prospects. Trends in Food Science \& Technology 80 (2018) 175-186. https://doi.org/10.1016/j.tifs.2018.08.005.

[90] N. Cai, C. Han, X. Luo, G. Chen, Q. Dai, F. Yu. Fabrication of Core/Shell Nanofibers with Desirable Mechanical and Antibacterial Properties by Pickering Emulsion Electrospinning. Macromolecular Materials and Engineering 302(3) (2016). https://doi.org/10.1002/mame.201600364.

[91] X. Wang, Y. Yuan, X. Huang, T. Yue. Controlled release of protein from core-shell nanofibers prepared by emulsion electrospinning based on green chemical. Journal of Applied Polymer Science 132(16) (2014). https://doi.org/10.1002/app.41811.

[92] A. Basar, S. Castro, S. Torres, J. Lagaron, S. Turkoglu S. Novel poly( $\varepsilon$-caprolactone)/gelatin wound dressings prepared by emulsion electrospinning with controlled release capacity of Ketoprofen antiinflammatory drug. Materials Science and Engineering C 81 (2017) 459-468. https://doi.org/10.1016/i.msec.2017.08.025.

[93] P. Pal, P. Srivas, P. Dadhich, B. Das, D. Maulik, S. Dhara. Nano-/Microfibrous Cotton-Wool-Like 3D Scaffold with Core-Shell Architecture by Emulsion Electrospinning for Skin Tissue Regeneration. ACS Biomaterials Science \& Engineering 3(12) (2017) 3563-3575. https://doi.org/10.1021/acsbiomaterials.7b00681.

[94] J. Hu, M. Prabhakaran, X. Ding, S. Ramakrishna. Emulsion electrospinning of polycaprolactone: influence of surfactant type towards the scaffold properties. Journal of Biomaterials Science Polymer Edition 26(1) (2015) 57-75. https://doi.org/10.1080/09205063.2014.982241.

[95] A. Moydeen, P. Ali, E. Aboelfetoh, S. Al-Deyab, M. El-Newehy. Fabrication of electrospun poly(vinyl alcohol)/dextran nanofibers via emulsion process as drug delivery system: Kinetics and in vitro release study. International Journal of Biological Macromolecules 116 (2018) 1250-1259. https://doi.org/10.1016/j.ijbiomac.2018.05.130. 
[96] R. Nayak, I. Kyratzis, Y. Truong, R. Padhye, L. Arnold, G. Peeters. Fabrication and Characterisation of Nanofibres by Meltblowing and Melt Electrospinning. Advanced Materials Research 472 (2012) 1294-1299. https://doi.org/10.4028/www.scientific.net/AMR.472-475.1294.

[97] Y. Qin, L. Cheng, Y. Zhang, X. Chen, X. Wang, X. He. Efficient preparation of poly(lactic acid) nanofibers by melt differential electrospinning with addition of acetyl tributyl citrate. Journal of Applied Polymer Science 135(31) (2018) 46554. https://doi.org/10.1002/app.46554.

[98] M. Muerza, D. Haylock, D. Hutmacher, P. Dalton. Melt Electrospinning and Its Technologization in Tissue Engineering. Tissue Engineering Part B: Reviews 21(2) (2014) 187-202. https://doi.org/10.1089/ten.TEB.2014.0347.

[99] M. Yamamoto, H. Yamane. Melt electrospinning: Electrodynamics and spinnability. Polymer 132 (2017) 206-215. https://doi.org/10.1016/i.polymer.2017.11.006.

[100] N. Bhardway, S. Kundu. Electrospinning: A fascinating fiber fabrication technique. Biotechnology Advances 28(3) (2010) 325-347. https://doi.org/10.1016/i.biotechadv.2010.01.004.

[101] D. Lv, M. Zhu, Z. Jiang, S. Jiang, Q. Zhang, R. Xiong. Green Electrospun Nanofibers and Their Application in Air Filtration. Macromolecular Materials and Engineering 303(12) (2018). https://doi.org/10.1002/mame.201800336.

[102] T. Brown, P. Dalton, D. Hutmacher. Melt electrospinning today: An opportune time for an emerging polymer process. Progress in Polymer Science 56 (2016) 116-166. https://doi.org/10.1016/i.progpolymsci.2016.01.001.

[103] Z. Li, D. Xiao, Y. Xu, Y. Miao, N. Xin, Z. Yong, L. Yun. Recent advances in melt electrospinning. RSC Advances 6(58) (2016) 53400-53414. https://doi.org/10.1039/C6RA09558E.

[104] L. Larrondo, R. Manley. Electrostatic fiber spinning from polymer melts. I. Experimental observations on fiber formation and properties. Journal of Polymer Science: Polymer Physics Edition 19(6) (1981) 909-20. https://doi.org/10.1002/pol.1981.180190601.

[105] L. Larrondo, R. Manley. Electrostatic fiber spinning from polymer melts. II. Examination of the flow field in an electrically driven jet. Journal of Polymer Science: Polymer Physics Edition 19(6) (1981) 921-32. https://doi.org/10.1002/pol.1981.180190602.

[106] L. Larrondo, R. Manley. Electrostatic fiber spinning from polymer melts. III. Electrostatic deformation of a pendant drop of polymer melt. Journal of Polymer Science: Polymer Physics Edition 19(6) (1981) 933-40. https://doi.org/10.1002/pol.1981.180190603.

[107] Y. Weimin, L. Haoyi. Principle and equipment of polymer melt differential electrospinning preparing ultrafine fiber. Materials Science and Engineering 64 (2014) 012013. https://doi.org/10.1088/1757899X/64/1/012013.

[108] H. Li, H. Chen, X. Zhong, W. Wu, Y. Ding, W. Yang. Interjet distance in needleless melt differential electrospinning with umbellate nozzles. Journal of Applied Polymer Science 131(15) (2014) 40515. https://doi.org/10.1002/app.40515.

[109] A. Blakney, C. Ball, E. Krogstad, K. Woodrow. Electrospun fibers for vaginal anti-HIV drug delivery. Antiviral Research 100 (2013) 9-16. https://doi.org/10.1016/j.antiviral.2013.09.022.

[110] B. Singh, N. Panda, R. Mund, K. Pramanik. Carboxymethyl cellulose enables silk fibroin nanofibrous scaffold with enhanced biomimetic potential for bone tissue engineering application. Carbohydrate Polymers 151 (2016) 335-347. https://doi.org/10.1016/j.carbpol.2016.05.088.

[111] L. Preem, M. Mahmoudzadeh, M. Putrinš, A. Meos, I. Laidmäe, T. Romann. Interactions between Chloramphenicol, Carrier Polymers, and Bacteria-Implications for Designing Electrospun Drug Delivery Systems Countering Wound Infection. Molecular Pharmaceutics 14(12) (2017) 4417-4430. https://doi.org/10.1021/acs.molpharmaceut.7b00524.

[112] J. Yao, S. Zhang, W. Li, Z. Du, Y. Li. In vitro drug controlled-release behavior of an electrospun modified poly(lactic acid)/bacitracin drug delivery system. RSC Advances 6(1) (2015) 515-521. https://doi.org/10.1039/C5RA22467E.

[113] S. Thakkar, M. Misra. Electrospun polymeric nanofibers: New horizons in drug delivery. European Journal of Pharmaceutical Sciences 107 (2017) 148-167. https://doi.org/10.1016/i.ejps.2017.07.001. 
[114] D. Kai, S. Liow, X. Loh. Biodegradable polymers for electrospinning: Towards biomedical applications. Materials Science and Engineering: C 45 (2014) 659-670. https://doi.org/10.1016/i.msec.2014.04.$\underline{051}$.

[115] J. Ding, J. Zhang, J. Li, D. Li, C. Xiao, H. Xiao. Electrospun polymer biomaterials. Progress in Polymer Science 90 (2019) 1-34. https://doi.org/10.1016/i.progpolymsci.2019.01.002.

[116] C. Luo, E. Stride, M. Edirisinghe. Mapping the Influence of Solubility and Dielectric Constant on Electrospinning Polycaprolactone Solutions. Macromolecules 45(11) (2012) 4669-4680. https://doi.org/10.1021/ma300656u.

[117] J. Schiffman, C. Schauer. A Review: Electrospinning of Biopolymer Nanofibers and their Applications. Polymer Reviews 48(2) (2008) 317-352. https://doi.org/10.1080/15583720802022182.

[118] M. Maniruzzaman, D. Morgan, A. Mendham, J. Pang, M. Snowden, D. Douroumis. Drug-polymer intermolecular interactions in hot-melt extruded solid dispersions. International Journal of Pharmaceutics 443(1) (2013) 199-208. https://doi.org/10.1016/j.ijpharm.2012.11.048.

[119] F. Meng, A. Trivino, D. Prasad, H. Chauhan. Investigation and correlation of drug polymer miscibility and molecular interactions by various approaches for the preparation of amorphous solid dispersions. European Journal of Pharmaceutical Sciences 71 (2015) 12-24. https://doi.org/10.1016/i.ejps.2015.02.003.

[120] A. Prudic, Y. Ji, G. Sadowski. Thermodynamic Phase Behavior of API/Polymer Solid Dispersions. Molecular Pharmaceutics 11(7) (2014) 2294-2304. https://doi.org/10.1021/mp400729x.

[121] A. Sadeghi, H. Nazem, M. Rezakazemi, S. Shirazian. Predictive construction of phase diagram of ternary solutions containing polymer/solvent/nonsolvent using modified Flory-Huggins model. Journal of Molecular Liquids 263 (2018) 282-287. https://doi.org/10.1016/j.molliq.2018.05.015.

[122] H. Lu, S. Du. A phenomenological thermodynamic model for the chemo-responsive shape memory effect in polymers based on Flory-Huggins solution theory. Polymer Chemistry 5(4) (2014) 11551162. https://doi.org/10.1039/C3PY01256E.

[123] C. Donnelly, Y. Tian, C. Potter, D. Jones, G. Andrews. Probing the Effects of Experimental Conditions on the Character of Drug-Polymer Phase Diagrams Constructed Using Flory-Huggins Theory. Pharmaceutical Research 32(1) (2015) 167-179. https://doi.org/10.1007/s11095-014-1453-9.

[124] M. Knopp, L. Tajber, Y. Tian, N. Olesen, D. Jones, A. Kozyra. Comparative Study of Different Methods for the Prediction of Drug-Polymer Solubility. Molecular Pharmaceutics 12(9) (2015) 3408-3419. https://doi.org/10.1021/acs.molpharmaceut.5b00423.

[125] A. Gravelle, M. Davidovich, A. Zetzl, S. Barbut, A. Marangoni. Influence of solvent quality on the mechanical strength of ethylcellulose oleogels. Carbohydrate Polymers 135 (2016) 169-79. https://doi.org/10.1016/i.carbpol.2015.08.050.

[126] C. Luo, M. Nangrejo, M. Edirisinghe. A novel method of selecting solvents for polymer electrospinning. Polymer 51(7) (2010) 1654-1662. https://doi.org/10.1016/i.polymer.2010.01.031.

[127] S. Mahalingam, B. Raimi, D. Craig, M. Edirisinghe. Solubility-spinnability map and model for the preparation of fibres of polyethylene (terephthalate) using gyration and pressure. Chemical Engineering Journal 280 (2015) 344-353. https://doi.org/10.1016/i.cej.2015.05.114.

[128] C. Mathis, M. Divandari, R. Simic, V. Naik, E. Benetti, L. Isa. ATR-IR Investigation of Solvent Interactions with Surface-Bound Polymers. Langmuir 32(30) (2016) 7588-7595. https://doi.org/10.1021/acs.langmuir.6b02086.

[129] J. Jacob, J. Haponiuk, S. Thomas, S. Gopi. Biopolymer based nanomaterials in drug delivery systems: A review. Materials Today Chemistry 9 (2018) 43-55. https://doi.org/10.1016/i.mtchem.2018.05.002.

[130] S. Khatsee, D. Daranarong, W. Punyodom, P. Worajittiphon. Electrospinning polymer blend of PLA and PBAT: Electrospinnability-solubility map and effect of polymer solution parameters toward application as antibiotic-carrier mats. Journal of Applied Polymer Science 135(28) (2018). https://doi.org/10.1002/app.46486.

[131] M. Rashid, Q. Zaid, S. Tajuddin. Chapter 11 - Trends in Nanotechnology for Practical Applications. In: S. Mohapatra, S. Ranjan, N. Dasgupta, R. Kumar, S. Thomas. Applications of Targeted Nano Drugs and 
Delivery Systems: Nanoscience and Nanotechnology in Drug Delivery, Elsevier, 2018. p. 297-325. https://doi.org/10.1016/B978-0-12-814029-1.00011-9.

[132] V. Chavda. Chapter 1 - Nanotherapeutics and Nanobiotechnology. In: S. Mohapatra, S. Ranjan, N. Dasgupta, R. Kumar, S. Thomas. Applications of Targeted Nano Drugs and Delivery Systems: Nanoscience and Nanotechnology in Drug Delivery, Elsevier, 2018, p. 1-13. https://doi.org/10.1016/B978-0-12-814029-1.00001-6.

[133] F. Lopez, T. Ernest, C. Tuleu, M. Gul. Formulation approaches to pediatric oral drug delivery: benefits and limitations of current platforms. Expert Opinion on Drug Delivery. 12(11) (2015) 1727-1740. https://doi.org/10.1517/17425247.2015.1060218.

[134] A. Aleksovski, R. Dreu, M. Gašperlin, O. Planinšek. Mini-tablets: a contemporary system for oral drug delivery in targeted patient groups. Expert Opinion on Drug Delivery 12(1) (2015) 65-84. https://doi.org/10.1517/17425247.2014.951633.

[135] L. Castillo, R. Vargas, G. Carazo, G. Madrigal, B. Calvo, E. Baltodano. Development of immediate release Rupatadine fumarate $10 \mathrm{mg}$ tablets: A Quality by Design (QbD) approach. Drug Development and Industrial Pharmacy 45(10) (2019) 1674-1681. https://doi.org/10.1080/03639045.2019 .1652637$.

[136] U. Maver, T. Velnar, M. Gaberšček, O. Planinšek, M. Finšgar. Recent progressive use of atomic force microscopy in biomedical applications. Trends in Analytical Chemistry 80 (2016) 96-111. https://doi.org/10.1016/j.trac.2016.03.014.

[137] B. Mittal. Chapter 2 - Pharmacokinetics and Preformulation. In: B. Mittal. How to Develop Robust Solid Oral Dosage Forms from Conception to Post-Approval, Academic Press, 2017 p. 17-37. https://doi.org/10.1016/B978-0-12-804731-6.00002-9.

[138] K. Göke, T. Lorenz, A. Repanas, F. Schneider, D. Steiner, K. Baumann. Novel strategies for the formulation and processing of poorly water-soluble drugs. European Journal of Pharmaceutics and Biopharmaceutics 126 (2018) 40-56. https://doi.org/10.1016/i.ejpb.2017.05.008.

[139] G. Amidon, H. Lennernäs, V. Shah, J. Crison. A theoretical basis for a biopharmaceutic drug classification: the correlation of in vitro drug product dissolution and in vivo bioavailability. Pharmaceutical Research 12(3) (1995) 413-420. http://dx.doi.org/10.1023/A:1016212804288.

[140] L. Yu, G. Amidon, J. Polli, H. Zhao, M. Mehta, D. Conner. Biopharmaceutics classification system: the scientific basis for biowaiver extensions. Pharmaceutical Research 19(7) (2002) 921-925. http://dx.doi.org/10.1023/A:1016473601633.

[141] R. Kamble, S. Gaikwad, A. Maske, S. Patil. Fabrication of electrospun nanofibres of BCS II drug for enhanced dissolution and permeation across skin. Journal of Advanced Research 7(3) (2016) 483489. http://dx.doi.org/10.1016/j.jare.2016.03.009.

[142] S. Baghel, H. Cathcart, N. O'Reilly. Polymeric Amorphous Solid Dispersions: A Review of Amorphization, Crystallization, Stabilization, Solid-State Characterization, and Aqueous Solubilization of Biopharmaceutical Classification System Class II Drugs. Journal of Pharmaceutical Sciences 105(9) (2016) 2527-2544. https://doi.org/10.1016/j.xphs.2015.10.008.

[143] S. Kumar, R. Kaur, R. Rajput, M. Singh. Bio Pharmaceutics Classification System (BCS) Class IV Drug Nanoparticles: Quantum Leap to Improve Their Therapeutic Index. Advanced Pharmaceutical Bulletin 8(4) (2018) 617-625. https://doi.org/10.15171/apb.2018.070.

[144] A. Jacobsen, A. Krupa, M. Brandl, A. Bauer. High-Throughput Dissolution/Permeation Screening-A 96Well Two-Compartment Microplate Approach. Pharmaceutics 11(5) (2019) 227. https://doi.org/10.3390/pharmaceutics11050227.

[145] T. Sou, C. Bergström. Automated assays for thermodynamic (equilibrium) solubility determination. Drug Discovery Today: Technologies 27 (2018) 11-19. https://doi.org/10.1016/i.ddtec.2018.04.004.

[146] Z. Nagy, A. Balogh, B. Démuth, H. Pataki, T. Vigh, B. Szabó. High speed electrospinning for scaled-up production of amorphous solid dispersion of itraconazole. International Journal of Pharmaceutics 480(1-2) (2015) 137-142. https://doi.org/10.1016/j.ijpharm.2015.01.025. 
[147] U. Paaver, I. Tamm, I. Laidmäe, A. Lust, K. Kirsimäe, P. Veski. Soluplus graft copolymer: potential novel carrier polymer in electrospinning of nanofibrous drug delivery systems for wound therapy. Biomed Research International (2014) 789765. https://doi.org/10.1155/2014/789765.

[148] R. Zelkó, D. Lamprou, I. Sebe. Recent Development of Electrospinning for Drug Delivery. Pharmaceutics 12(1) (2020) 5. https://doi.org/10.3390/pharmaceutics12010005.

[149] L. Kenry, C. Lim. Nanofiber technology: current status and emerging developments. Progress in Polymer Science 70 (2017) 1-17. https://doi.org/10.1016/i.progpolymsci.2017.03.002.

[150] A. Bhatia, S. Chopra, K. Nagpal, P. Kishore, M. Tekade, R. Tekade. Chapter 2 - Polymorphism and its Implications in Pharmaceutical Product Development. In: R. Tekade. Dosage Form Design Parameters, Academic Press, 2018, p. 31-65. https://doi.org/10.1016/B978-0-12-814421-3.00002-6.

[151] B. Poller, C. Strachan, R. Broadbent, G. Walker. A minitablet formulation made from electrospun nanofibers. European Journal of Pharmaceutics and Biopharmaceutics 114 (2017) 213-220. https://doi.org/10.1016/j.ejpb.2017.01.022.

[152] P. Vass, E. Szabó, A. Domokos, E. Hirsch, D. Galata, B. Farkas. Scale-up of electrospinning technology: Applications in the pharmaceutical industry. WIREs Nanomedicine and Nanobiotechnology (2019) 124. https://doi.org/10.1002/wnan.1611.

[153] P. Vass, E. Hirsch, R. Kóczián, B. Démuth, A. Farkas, C. Fehér. Scaled-Up Production and Tableting of Grindable Electrospun Fibers Containing a Protein-Type Drug. Pharmaceutics 11(7) (2019) 329. https://doi.org/10.3390/pharmaceutics11070329.

[154] M. Abrigo, S. McArthur, P. Kingshott. Electrospun nanofibers as dressings for chronic wound care: advances, challenges, and future prospects. Macromolecular Bioscience 14(6) (2014) 772-792. https://doi.org/10.1002/mabi.201300561.

[155] J. Boateng, O. Catanzano. Advanced Therapeutic Dressings for Effective Wound Healing--A Review. Journal of Pharmaceutical Sciences 104(11) (2015) 3653-3680. https://doi.org/10.1002/jps.24610.

[156] K. Ye, H. Kuang, Z. You, Y. Morsi, X. Mo. Electrospun Nanofibers for Tissue Engineering with Drug Loading and Release. Pharmaceutics 11(4) (2019). https://doi.org/10.3390/pharmaceutics11040182.

[157] H. Lian, Z. Meng. Melt electrospinning vs. solution electrospinning: A comparative study of drugloaded poly ( $\varepsilon$-caprolactone) fibres. Materials Science and Engineering: C 74 (2017) 117-123. https://doi.org/10.1016/j.msec.2017.02.024.

[158] T. Zhu, S. Chen, W. Li, J. Lou, J. Wang. Flurbiprofen axetil loaded coaxial electrospun poly(vinyl pyrrolidone)-nanopoly(lactic-co-glycolic acid) core-shell composite nanofibers: Preparation, characterization, and anti-adhesion activity. Journal of Applied Polymer Science 132(22) (2015). https://doi.org/10.1002/app.41982.

[159] M. Shishir, L. Xie, C. Sun, X. Zheng, W. Chen. Advances in micro and nano-encapsulation of bioactive compounds using biopolymer and lipid-based transporters. Trends in Food Science \& Technology $\mathbf{7 8}$ (2018) 34-60. https://doi.org/10.1016/j.tifs.2018.05.018.

[160] P. Wen, M. Zong, R. Linhardt, K. Feng, H. Wu. Electrospinning: A novel nano-encapsulation approach for bioactive compounds. Trends in Food Science \& Technology 70 (2017) 56-68. https://doi.org/10.1016/i.tifs.2017.10.009.

[161] P. Wen, Y. Wen, M. Zong, R. Linhardt, H. Wu. Encapsulation of Bioactive Compound in Electrospun Fibers and Its Potential Application. Journal of Agricultural and Food Chemistry 65(42) (2017) 91619179. https://doi.org/10.1021/acs.jafc.7b02956.

[162] M. Ruiz, M. Volonté. Biopharmaceutical relevance of the comparison of dissolution profiles: proposal of a combined approach. Dissolution Technologies (2014) 32-43. http://dx.doi.org/ 10.14227/DT210114P32.

[163] J. Mašek, D. Lubasová, R. Lukáč, P. Turánek, P. Kulich, J. Plocková. Multi-layered nanofibrous mucoadhesive films for buccal and sublingual administration of drug-delivery and vaccination nanoparticles - important step towards effective mucosal vaccines. Journal of Controlled Release $\mathbf{2 4 9}$ (2017) 183-95. https://doi.org/10.1016/i.jconrel.2016.07.036. 
[164] R. Ricarte, Z. Li, L. Johnson, J. Ting, T. Reineke, F. Bates. Direct Observation of Nanostructures during Aqueous Dissolution of Polymer/Drug Particles. Macromolecules 50(8) (2017) 3143-3152. https://doi.org/10.1021/acs.macromol.7b00372.

[165] S. Qi, D. Craig. Recent developments in micro- and nanofabrication techniques for the preparation of amorphous pharmaceutical dosage forms. Advanced Drug Delivery Reviews 100 (2016) 67-84. https://doi.org/10.1016/i.addr.2016.01.003.

[166] A. Mendes, C. Gorzelanny, N. Halter, S. Schneider, I. Chronakis. Hybrid electrospun chitosanphospholipids nanofibers for transdermal drug delivery. International Journal of Pharmaceutics 510(1) (2016) 48-56. https://doi.org/10.1016/i.ijpharm.2016.06.016.

[167] A. Gencturk, E. Kahraman, S. Güngör, G. Özhan, Y. Özsoy, A. Sarac. Polyurethane/hydroxypropyl cellulose electrospun nanofiber mats as potential transdermal drug delivery system: characterization studies and in vitro assays. Artificial Cells, Nanomedicine, and Biotechnology 45(3) (2017) 655-664. https://doi.org/10.3109/21691401.2016.1173047.

[168] R. Najafi, M. Ali, R. Faridi, A. Amani. Preparation of an ascorbic acid/PVA-chitosan electrospun mat: a core/shell transdermal delivery system. RSC Advances 5(62) (2015) 50462-50469. https://doi.org/10.1039/C5RA03813H.

[169] K. Nazari, E. Kontogiannidou, R. Ahmad, A. Gratsani, M. Rasekh, M. Arshad. Development and characterisation of cellulose based electrospun mats for buccal delivery of non-steroidal antiinflammatory drug (NSAID). European Journal of Pharmaceutical Sciences 102 (2017) 147-155. https://doi.org/10.1016/i.ejps.2017.02.033.

[170] P. Szabó, T. Daróczi, G. Tóth, R. Zelkó. In vitro and in silico investigation of electrospun terbinafine hydrochloride-loaded buccal nanofibrous sheets. Journal of Pharmaceutical and Biomedical Analysis 30 (2016) 156-159. https://doi.org/10.1016/i.jpba.2016.08.021.

[171] E. Adeli. Irbesartan-loaded electrospun nanofibers-based PVP K90 for the drug dissolution improvement: Fabrication, in vitro performance assessment, and in vivo evaluation. Journal of Applied Polymer Science 132(27) (2015). https://doi.org/10.1002/app.42212.

[172] V. Chavda. Chapter 4 - Nanobased Nano Drug Delivery: A Comprehensive Review. In: S. Mohapatra, S. Ranjan, N. Dasgupta, R. Kumar, S. Thomas. Applications of Targeted Nano Drugs and Delivery Systems: Nanoscience and Nanotechnology in Drug Delivery, Elsevier, 2018, p. 69-92. https://doi.org/10.1016/B978-0-12-814029-1.00004-1.

[173] S. Shahriar, J. Mondal, M. Hasan, V. Revuri, D. Lee, Y. Lee. Electrospinning Nanofibers for Therapeutics Delivery. Nanomaterials 9(4) (2019) 532. https://doi.org/10.3390/nano9040532.

[174] A. Repanas, S. Andriopoulou, B. Glasmacher. The significance of electrospinning as a method to create fibrous scaffolds for biomedical engineering and drug delivery applications. Journal of Drug Delivery Science and Technology 31 (2016) 137-46. https://doi.org/10.1016/i.jddst.2015.12.007.

[175] M. Saeedi, M. Eslamifar, K. Khezri, S. Maleki. Applications of nanotechnology in drug delivery to the central nervous system. Biomedicine \& Pharmacotherapy 111 (2019) 666-675. https://doi.org/10.1016/j.biopha.2018.12.133.

[176] S. Maleki, F. Lotfipour, M. Barzegar, M. Zarrintan, K. Adibkia. Ciprofloxacin HCl-loaded calcium carbonate nanoparticles: preparation, solid state characterization, and evaluation of antimicrobial effect against Staphylococcus aureus. Artificial Cells, Nanomedicine, and Biotechnology 45(3) (2017) 535-543. https://doi.org/10.3109/21691401.2016.1161637.

[177] A. Akhgari, Z. Shakib, S. Sanati. A review on electrospun nanofibers for oral drug delivery. Nanomedicine Journal 4(4) (2017) 197-207.

[178] R. Ravikumar, M. Ganesh, V. Senthil, Y. Ramesh, S. Jakki, E. Choi. Tetrahydro curcumin loaded PCLPEG electrospun transdermal nanofiber patch: Preparation, characterization, and in vitro diffusion evaluations. Journal of Drug Delivery Science and Technology 44 (2018) 342-348. https://doi.org/10.1016/j.jddst.2018.01.016.

[179] A. Ammar. Polymeric Nanoparticles and Nanofibers for Local Delivery of Poorly Soluble Drugs. Recent Advances in Nanotechnology (2019). https://doi.org/10.11159/nddte19.116. 
[180] E. Torres, G. Pérez, A. Serrano, D. Grande, R. Vera, J. Cornejo. Drugs Loaded into Electrospun Polymeric Nanofibers for Delivery. Journal of Pharmacy and Pharmaceutical Sciences 22(1) (2019) 313-331. https://doi.org/10.18433/ipps29674.

[181] U. Paaver, J. Heinämäki, I. Laidmäe, A. Lust, J. Kozlova, E. Sillaste. Electrospun nanofibers as a potential controlled-release solid dispersion system for poorly water-soluble drugs. International Journal of Pharmaceutics 479(1) (2015) 252-60. https://doi.org/10.1016/i.ijpharm.2014.12.024.

[182] R. Rajput, J. Narkhede, J. Naik. Nanogels as nanocarriers for drug delivery: A review. ADMET and DMPK 8(1) (2020) 1-15. http://dx.doi.org/10.5599/admet.724.

[183] G. Yazgan, A. Popa, R. Rossi, K. Maniura, L. Puigmartí, D. Crespy. Tunable release of hydrophilic compounds from hydrophobic nanostructured fibers prepared by emulsion electrospinning. Polymer 66 (2015) 268-276. https://doi.org/10.1016/i.polymer.2015.04.045.

[184] Z. Cui, Z. Zheng, L. Lin, J. Si, Q. Wang, X. Peng. Electrospinning and crosslinking of polyvinyl alcohol/chitosan composite nanofiber for transdermal drug delivery. Advances in Polymer Technology 37(6) (2018) 917-928. https://doi.org/10.1002/adv.21850.

[185] S. Jin, A. Yousaf, K. Kim, D. Kim, J. Kim. Influence of hydrophilic polymers on functional properties and wound healing efficacy of hydrocolloid based wound dressings. International Journal of Pharmaceutics 501(1) (2016) 160-166. https://doi.org/10.1016/i.ijpharm.2016.01.044.

[186] M. Ghori, B. Conway. Hydrophilic Matrices for Oral Control Drug Delivery. American Journal of Pharmacological Sciences 3(5) (2015) 103-109. https://doi.org/10.1016/10.12691/ajps-3-5-1.

[187] M. Irfan, S. Rabel, Q. Bukhtar, M. Qadir, F. Jabeen, A. Khan. Orally disintegrating films: A modern expansion in drug delivery system. Saudi Pharmaceutical Journal 24(5) (2016) 537-546. https://doi.org/10.1016/j.jsps.2015.02.024.

[188] A. Srivastava, T. Yadav, S. Sharma, A. Nayak, A. Kumari, N. Mishra. Polymers in Drug Delivery. Journal of Biosciences and Medicines 4(1) (2015) 69-84. https://doi.org/10.4236/ibm.2016.41009.

[189] V. Gordon, G. Marom, S. Magdassi. Formation of hydrophilic nanofibers from nanoemulsions through electrospinning. International Journal of Pharmaceutics 478(1) (2015) 172-179. https://doi.org/10.1016/j.ijpharm.2014.11.038.

[190] K. Ghosal, A. Manakhov, L. Zajičková, S. Thomas. Structural and Surface Compatibility Study of Modified Electrospun Poly( $\varepsilon$-caprolactone) (PCL) Composites for Skin Tissue Engineering. AAPS PharmSciTech 18(1) (2017) 72-81. https://doi.org/10.1208/s12249-016-0500-8.

[191] K. Ghosal, A. Chandra, S. Roy, C. Agatemor. Electrospinning over Solvent Casting: Tuning of Mechanical Properties of Membranes. Scientific Reports 8(1) (2018) 1-9. https://doi.org/10.1038/s41598-018-23378-3.

[192] A. Aydogdu, G. Sumnu, S. Sahin. A novel electrospun hydroxypropyl methylcellulose/polyethylene oxide blend nanofibers: Morphology and physicochemical properties. Carbohydrate Polymers 181 (2018) 234-246. https://doi.org/10.1016/j.carbpol.2017.10.071.

[193] X. Zhao, J. Zhao, Z. Lin, G. Pan, Y. Zhu, Y. Cheng. Self-coated interfacial layer at organic/inorganic phase for temporally controlling dual-drug delivery from electrospun fibers. Colloids and Surfaces $B$ : Biointerfaces 130 (2015) 1-9. https://doi.org/10.1016/i.colsurfb.2015.03.058.

[194] A. Haider, S. Haider, I. Kang. A comprehensive review summarizing the effect of electrospinning parameters and potential applications of nanofibers in biomedical and biotechnology. Arabian Journal of Chemistry 11(8) (2018) 1165-1188. https://doi.org/10.1016/j.arabjc.2015.11.015.

[195] L. Jørgensen, K. Qvortrup, I. Chronakis. Phospholipid electrospun nanofibers: effect of solvents and co-axial processing on morphology and fiber diameter. RSC Advances 5(66) (2015) 53644-53652. https://doi.org/10.1039/C5RA10498J.

[196] L. Weng, J. Xie. Smart electrospun nanofibers for controlled drug release: recent advances and new perspectives. Current Pharmaceutical Design 21(15) (2015) 1944-1959.

[197] C. Alvarez, A. Concheiro. Smart drug delivery systems: from fundamentals to the clinic. Chemical Communications 50(58) (2014) 7743-7765. https://doi.org/10.1039/C4CC01429D. 
[198] A. Goyal, G. Rath, C. Faujdar, B. Malik. Chapter 2 - Application and Perspective of pH-Responsive Nano Drug Delivery Systems. In: S. Mohapatra, S. Ranjan, N. Dasgupta, R. Kumar, S. Thomas. Applications of Targeted Nano Drugs and Delivery Systems: Nanoscience and Nanotechnology in Drug Delivery, Elsevier, 2018, p. 15-33. https://doi.org/10.1016/B978-0-12-814029-1.00002-8.

[199] C. Dwivedi, H. Pandey, C. Pandey, P. Ramteke. Nanofibre Based Smart Pharmaceutical Scaffolds for Wound Repair and Regenerations. Current Pharmaceutical Design 22(11) (2016) 1460-1471. https://doi.org/10.2174/1381612822666151215103553.

[200] C. Yang, D. Yu, D. Pan, X. Liu, X. Wang, S. Bligh. Electrospun pH-sensitive core-shell polymer nanocomposites fabricated using a tri-axial process. Acta Biomaterialia 35 (2016) 77-86. https://doi.org/10.1016/j.actbio.2016.02.029.

[201] H. Frizzell, T. Ohlsen, K. Woodrow. Protein-loaded emulsion electrospun fibers optimized for bioactivity retention and $\mathrm{pH}$-controlled release for peroral delivery of biologic therapeutics. International Journal of Pharmaceutics 533(1) (2017) 99-110. https://doi.org/10.1016/j.ijpharm.2017.09.043.

[202] A. Akhgari, Z. Heshmati, H. Afrasiabi, F. Sadeghi, A. Sabbagh, B. Sharif. Indomethacin electrospun nanofibers for colonic drug delivery: In vitro dissolution studies. Colloids and Surfaces B: Biointerfaces 152 (2017) 29-35. https://doi.org/10.1016/i.colsurfb.2016.12.035.

[203] L. Liu, S. Bai, H. Yang, S. Li, J. Quan, L. Zhu. Controlled release from thermo-sensitive PNVCL-co-MAA electrospun nanofibers: The effects of hydrophilicity/hydrophobicity of a drug. Materials Science and Engineering: C 67 (2016) 581-589. https://doi.org/10.1016/i.msec.2016.05.083.

[204] H. Li, K. Liu, Q. Sang, G. Williams, J. Wu, H. Wang. A thermosensitive drug delivery system prepared by blend electrospinning. Colloids and Surfaces B: Biointerfaces 159 (2017) 277-283. https://doi.org/10.1016/i.colsurfb.2017.07.058.

[205] A. Sasikala, A. Unnithan, Y. Yun, C. Park, C. Kim. An implantable smart magnetic nanofiber device for endoscopic hyperthermia treatment and tumor-triggered controlled drug release. Acta Biomaterialia 31 (2016) 122-133. https://doi.org/10.1016/j.actbio.2015.12.015.

[206] B. Wang, H. Zheng, M. Chang, Z. Ahmad, J. Li. Hollow polycaprolactone composite fibers for controlled magnetic responsive antifungal drug release. Colloids and Surfaces B: Biointerfaces 145 (2016) 757-767. https://doi.org/10.1016/i.colsurfb.2016.05.092.

[207] M. Heidari, H. Bahrami, M. Ranjbar, P. Milan. Smart electrospun nanofibers containing $\mathrm{PCL} /$ gelatin/graphene oxide for application in nerve tissue engineering. Materials Science and Engineering: C 103 (2019) 109768. https://doi.org/10.1016/j.msec.2019.109768.

[208] A. Puiggalí, A. Cejudo, L. del Valle, C. Alemán. Smart Drug Delivery from Electrospun Fibers through Electroresponsive Polymeric Nanoparticles. ACS Applied Bio Materials 1(5) (2018) 1594-1605. https://doi.org/10.1021/acsabm.8b00459.

[209] H. Li, K. Liu, G. Williams, J. Wu, H. Wang. Dual temperature and $\mathrm{pH}$ responsive nanofiber formulations prepared by electrospinning. Colloids and Surfaces B: Biointerfaces 171 (2018) 142-149. https://doi.org/10.1016/i.colsurfb.2018.07.020.

[210] T. Yadavalli, S. Ramasamy, G. Chandrasekaran, I. Michael, H. Therese, R. Chennakesavulu. Dual responsive PNIPAM-chitosan targeted magnetic nanopolymers for targeted drug delivery. Journal of Magnetism and Magnetic Materials 380 (2015) 315-20. https://doi.org/10.1016/i.jmmm.2014.09.035 .

[211] C. Tran, P. Tran, T. Tran. pH-independent dissolution enhancement for multiple poorly water-soluble drugs by nano-sized solid dispersions based on hydrophobic-hydrophilic conjugates. Drug Development and Industrial Pharmacy 45(3) (2019) 514-519. https://doi.org/10.1080/03639045.2018.1562466.

[212] M. Chen, Y. Li, F. Besenbacher. Electrospun Nanofibers-Mediated On-Demand Drug Release. Advanced Healthcare Materials 3(11) (2014) 1721-1732. https://doi.org/10.1002/adhm.201400166.

[213] S. Demirci, A. Celebioglu, Z. Aytac, T. Uyar. pH-responsive nanofibers with controlled drug release properties. Polymer Chemistry 5(6) (2014) 2050-2056. https://doi.org/10.1039/C3PY01276J. 
[214] L. Liu, W. Yao, Y. Rao, X. Lu, J. Gao. pH-Responsive carriers for oral drug delivery: challenges and opportunities of current platforms. Drug Delivery 24(1) (2017) 569-581. https://doi.org/10.1080/10717544.2017.1279238.

[215] D. Ghosh, G. Chakrabarti. Chapter 6 - Thermoresponsive Drug Delivery Systems, Characterization and Application. I In: S. Mohapatra, S. Ranjan, N. Dasgupta, R. Kumar, S. Thomas. Applications of Targeted Nano Drugs and Delivery Systems: Nanoscience and Nanotechnology in Drug Delivery, Elsevier, 2018, p. 133-155. https://doi.org/10.1016/B978-0-12-814029-1.00006-5.

[216] L. Yi, Y. Wang, Y. Fang, M. Zhang, J. Yao, L. Wang. Development of core-sheath structured smart nanofibers by coaxial electrospinning for thermo-regulated textiles. RSC Advances 9(38) (2019) 21844-21851. https://doi.org/10.1039/C9RA03795K.

[217] J. Hu, H. Li, G. Williams, H. Yang, L. Tao, L. Zhu. Electrospun Poly(N-isopropylacrylamide)/Ethyl Cellulose Nanofibers as Thermoresponsive Drug Delivery Systems. Journal of Pharmaceutical Sciences 105(3) (2016) 1104-1112. https://doi.org/10.1016/S0022-3549(15)00191-4.

[218] X. Lin, D. Tang, Z. Yu, Q. Feng. Stimuli-responsive electrospun nanofibers from poly(Nisopropylacrylamide)-co-poly(acrylic acid) copolymer and polyurethane. Journal of Materials Chemistry B 2(6) (2014) 651-658. https://doi.org/10.1039/C3TB21519A.

[219] S. Wu, B. Wang, Z. Ahmad, J. Huang, M. Chang, J. Li. Surface modified electrospun porous magnetic hollow fibers using secondary downstream collection solvent contouring. Materials Letters 204 (2017) 73-76. https://doi.org/10.1016/j.matlet.2017.06.015.

[220] J. Kim, S. Zhu, Y. Gan, K. Forward. Magnetic Hyperthermia Behavior of Electrospun Polyvinylpyrrolidone (PVP) Nanofibers Containing Magnetic Oxide Materials. Advances in Research (2015) 84-91. https://doi.org/10.9734/AIR/2015/13547.

[221] C. Mortimer, C. Wright. The fabrication of iron oxide nanoparticle-nanofiber composites by electrospinning and their applications in tissue engineering. Biotechnol J 12(7) (2017). https://doi.org/10.1002/biot.201600693.

[222] S. Spadaro, M. Santoro, F. Barreca, A. Scala, S. Grimato, F. Neri. PEG-PLGA electrospun nanofibrous membranes loaded with Au@Fe2O3 nanoparticles for drug delivery applications. Frontiers in Physics 13(1) (2017) 136201. https://doi.org/10.1007/s11467-017-0703-9.

[223] H. Zhang, J. Xia, X. Pang, M. Zhao, B. Wang, L. Yang. Magnetic nanoparticle-loaded electrospun polymeric nanofibers for tissue engineering. Materials Science and Engineering: C 73 (2017) 537-543. https://doi.org/10.1016/i.msec.2016.12.116.

[224] R. Meyer, J. Green. Biodegradable polymer iron oxide nanocomposites: the future of biocompatible magnetism. Nanomedicine 10(23) (2015) 3421-34252015. https://doi.org/10.2217/nnm.15.165.

[225] J. Thévenot, H. Oliveira, O. Sandre, S. Lecommandoux. Magnetic responsive polymer composite materials. Chem. Soc. Rev. 42(2013) 7099-7116. https://doi.org/ 10.1039/C3CS60058K.

[226] G. Filipcsei, I. Csetneki, A. Szilágyi, M. Zrínyi. Magnetic Field-Responsive Smart Polymer Composites. In: Oligomers - Polymer Composites - Molecular Imprinting. Advances in Polymer Science. Springer, Berlin, (2007). https://doi.org/10.1007/12 2006104.

[227] G. Chen, J. Guo, J. Nie, G. Ma. Preparation, characterization, and application of PEO/HA core shell nanofibers based on electric field induced phase separation during electrospinning. Polymer $\mathbf{8 3}$ (2016) 12-19. https://doi.org/10.1016/i.polymer.2015.12.002.

[228] G. Xie, Y. Wang, X. Han, Y. Gong, J. Wang, J. Zhang. Pulsed Electric Fields on Poly-l-(lactic acid) Melt Electrospun Fibers. Industrial \& Engineering Chemistry Research 55(26) (2016) 7116-7123. https://doi.org/10.1021/acs.iecr.6b00958.

[229] Q. Zhao, W. Lu, M. Wang. Modulating the release of vascular endothelial growth factor by negativevoltage emulsion electrospinning for improved vascular regeneration. Materials Letters 193 (2017) 14. https://doi.org/10.1016/i.matlet.2017.01.058.

[230] R. Cheng, F. Meng, C. Deng, H. Klok, Z. Zhong. Dual and multi-stimuli responsive polymeric nanoparticles for programmed site-specific drug delivery. Biomaterials 34(14) (2013) 3647-3657. https://doi.org/10.1016/i.biomaterials.2013.01.084. 
[231] H. Yuan, B. Li, K. Liang, X. Lou, Y. Zhang. Regulating drug release from $\mathrm{pH}$ - and temperatureresponsive electrospun CTS-g-PNIPAAm/poly(ethylene oxide) hydrogel nanofibers. Biomedical Materials 9(5) (2014). https://doi.org/10.1088/1748-6041/9/5/055001.

(C)2020 by the authors; licensee IAPC, Zagreb, Croatia. This article is an open-access article distributed under the terms and conditions of the Creative Commons Attribution license (http://creativecommons.org/licenses/by/3.0/) (cc)) EY 